\title{
Sovereign default: which shocks matter?
}

\author{
Bernardo Guimaraes*
}

April 2010

\begin{abstract}
This paper analyses a small open economy that wants to borrow from abroad, cannot commit to repay debt but faces costs if it decides to default. The model generates analytical expressions for the impact of shocks on the incentive compatible level of debt. Debt reduction generated by severe output shocks is no more than a couple of percentage points. In contrast, shocks to world interest rates can substantially affect the incentive compatible level of debt.

KEYWORDS: sovereign debt; default; world interest rates; output shocks.

Jel Classification: F34.
\end{abstract}

\section{Introduction}

What generates sovereign default? Which shocks are behind the episodes of debt crises we observe? The answer to the question is crucial to policy design. If we want to write contingent contracts, ${ }^{1}$ build and operate a sovereign debt restructuring mechanism, ${ }^{2}$ or an international lender of last resort, ${ }^{3}$ we need to know which economic variables are subject to shocks that significantly increase incentives for default or could take a country to "bankruptcy".

I investigate this question by studying a small open economy that wants to borrow from abroad, cannot commit to repay debt but faces costs if it decides to default. There is an incentive compatible level of sovereign debt — beyond which greater debt triggers default - and it fluctuates with economic conditions. The renegotiation process is costless and restores debt to its incentive compatible level. The model yields analytical expressions

\footnotetext{
${ }^{*}$ London School of Economics, Department of Economics, and Escola de Economia de Sao Paulo, FGV-SP; b.guimaraes@lse.ac.uk. I thank Giancarlo Corsetti, Nicola Gennaioli, Alberto Martin, Silvana Tenreyro, Alwyn Young and, especially, Francesco Caselli for helpful comments, several seminar participants for their inputs and Zsofia Barany and Nathan Foley-Fisher for excellent research assistance financed by STICERD.

${ }^{1}$ Borensztein and Mauro (2004) argue for GDP-indexed debt. Kletzer et al (1992) defend indexing debt payments to commodities prices.

${ }^{2}$ Krueger (2002) and Bolton and Jeanne (2007) argue for a sovereign debt restructuring mechanism.

${ }^{3}$ Fisher (1999) argues for an international lender of last resort.
} 
that allows us to quantify the impact of different shocks on the incentive compatible level of debt.

One important result from this framework is that shocks to domestic productivity (or output) do not generate sizable fluctuations in the incentive compatible level of debt. Following a severe output shock, debt relief of a couple of percentage points would restore incentive compatibility. This is consistent with some empirical evidence (Tomz and Wright, 2007), although most of the recent quantitative models on debt and default focus on output shocks. ${ }^{4}$ This result suggests that the literature has been focusing on the wrong type of shocks.

On the other hand, shocks to risk-free 'world' real interest rates are much more important. Debt relief in response to reasonable fluctuations in world interest rates is an order of magnitude higher than that generated by shocks to output. While a change in interest rates from $1 \%$ to $2 \%$ doubles the cost of servicing debt, a $1 \%$ fall in output reduces by just $1 \%$ the cost of not repaying. The large effect of shocks to world interest rates on debt default is present in some empirical work (Uribe and Yue, 2006).

Using data from the Latin American debt crisis of the 1980's, I compare the model's prediction of debt reduction with the observed debt relief. The increase in world interest rates at the beginning of the 1980's can solely account for over half of the debt forgiveness obtained by the main Latin American countries through the Brady agreements.

The model builds on the literature of endogenous sovereign debt and default (Eaton and Gersovitz (1981), Arellano (2008)). One of the key assumptions in the model is that if a country repudiated its debt, it would be excluded from capital markets and incur an output loss. ${ }^{5}$ The assumption of such costs is a simple way of modeling the costs that could be imposed on a country that defaults. Debt repudiation might inhibit foreign direct investment and undermine a country's capacity to obtain beneficial deals in multi-lateral organisations such as the WTO. In addition, creditors can threaten countries that might repudiate debt with sanctions such as the loss of access to short-term trade credit and seizure of assets. ${ }^{6}$

In reality, however, observed punishment for default is arguably tame and temporary. But that is, at least in part, because debtor and creditors renegotiate the debt and, sooner or later, a new agreement is reached. Although we rarely observe explicit contingent contracts, premium rates on borrowing and occasional debt reduction are ob-

\footnotetext{
${ }^{4}$ For example, Arellano (2008), Aguiar and Gopinath, (2006) and Yue (2010).

${ }^{5}$ The output cost of debt repudiation, as modeled here, is present in Cohen and Sachs (1986), Bulow and Rogoff (1989) and Arellano (2008), to name a few.

${ }^{6}$ For a discussion of such costs, see Bulow and Rogoff (1989), English (1996), Sturzenegger and Zettelmeyer (2006) and Tomz (2007).
} 
served, so contracts are contingent de facto even if not written as such. ${ }^{7}$ The possibility of renegotiation makes contracts contingent. ${ }^{8}$

Here, I assume that the borrower can costlessly call for debt renegotiation, but lenders have all the bargaining power in the renegotiation stage. In equilibrium, the assumption on bargaining power implies that debt renegotiation simply restores debt to its incentive compatible level. Costs, delays and further debt reductions associated with the renegotiation process might play an important role, but abstracting from them allows us to better understand the effects of different shocks on the incentive compatible level of debt. ${ }^{9}$

I begin with an endowment economy, where borrowers' impatience drives debt decisions. Then I move to a model with production, where borrowing occurs due to differences in the marginal productivity of capital. Models with endogenous decision of debt repayment and capital accumulation are not very tractable analytically. However, for some limiting cases, I can derive simple and intuitive analytical solutions for the level of debt and debt reduction ("haircut"). The method consists of taking first order approximations of the Bellman equations. I also solve the model numerically for non-limiting cases and show that the analytical solutions are good approximations.

The results on debt reduction for both economies are very similar. Debt reduction predicted by the model depends positively on the magnitude of the shocks and the persistence of states. Importantly, the output cost of defaulting, a variable which is difficult to measure, has no significant effect on debt relief as a fraction of the outstanding debt. So the conclusions on the quantitative effects of shocks do not rest on any particular value of this variable.

There are two key differences between the similar results for both economies. First, in the economy with capital, differences in the consumption-savings decisions for different states of the economy could influence decisions on debt and default. However, I show they produce no first-order effects on the incentive compatible level of debt, as they have only second order effects on the value functions. Second, growth prospects influence the level of debt and debt relief, but those effects are not large. The amount of capital influences

\footnotetext{
${ }^{7}$ Sovereign debt was analysed as an (implicitly) contingent claim by Grossman and Van Huyck (1988), Atkeson (1991) and Calvo and Kaminsky (1991) among others. Grossman and Van Huyck show that an equilibrium in which "excusable" default is allowed without sanctions can be sustained. Alfaro and Kanczuk's (2005) quantitative analysis builds on Grossman and Van Huyck. Calvo and Kaminsky (1991) take the optimal contract approach to study whether the small default premium paid by Latin American countries in the 1970's would be compatible with large debt reductions in the 1980's.

${ }^{8}$ Kocherlakota (1996) and Alvarez and Jermann (2000) analyse models where agents can trade contingent contracts but cannot commit to repay debt.

${ }^{9}$ Renegotiation in models of sovereign debt is studied by Bulow and Rogoff (1989), Fernandez and Rosenthal (1990) and Yue (2010). Kovrijnykh and Szentes (2007) study the return from debt overhang to the credit market.
} 
debt relief in both directions, rendering the result ambiguous. ${ }^{10}$ Therefore, the conclusions about the impact of shocks on the incentive compatible level of debt are basically the same in both economies.

Section 2 studies an endowment economy, Section 3 adds capital accumulation to the model, Section 4 contrasts the results with data from the Latin American debt forgiveness under the Brady Plan, Section 5 concludes. Most proofs and numerical exercises are in the appendix.

\section{Endowment economy}

In this section, I consider a discrete time model of an open endowment economy that can borrow from abroad, but cannot commit to repay its debts. The focus of the paper is sovereign debt, so all results in this paper are derived from the point of a view of a domestic planner. ${ }^{11}$

The economy is populated by a continuum of infinitely lived agents whose preferences are aggregated to form the usual representative agent utility function:

$$
\sum_{t=0}^{\infty} \beta^{t} u\left(c_{t}\right)
$$

where $\beta \in(0,1)$ is the subjective time discount factor, $c_{t}$ is consumption at time $t$ and $u($.$) is the felicity function that satisfies the Inada conditions.$

I model debt default costs as an instantaneous permanent fall in output and loss of access to capital markets. The permanent fall specifically captures the loss that a country suffers by taking an antagonistic position towards the rest of the world and never repaying a cent of its debts. I denote by $\gamma$ the fraction of output lost due to default, so output is given by:

$$
y_{t}=\left\{\begin{array}{l}
y_{t}, \text { if it has never defaulted } \\
(1-\gamma) y_{t}, \text { if it has ever defaulted }
\end{array}\right.
$$

In the model this is out-of-equilibrium behaviour, which corresponds to never observing such action in reality. For this reason, it is difficult to obtain an estimate of $\gamma$, but the main results of this paper do not depend on the value of $\gamma$.

\footnotetext{
${ }^{10}$ In the numerical examples, debt relief depends negatively on the level of capital.

${ }^{11}$ In the standard Ramsey model, the central planner solution and the decentralised equilibrium are the same. However, that is not true without commitment to repay debt. The distinction between the central planner solution and the decentralised allocation is analysed by Kehoe and Perri (2004) and Jeske (2006). Kehoe and Perri (2004) show that the central planner solution can be decentralised if the central government is in charge of deciding about defaulting or not and taxes capital income to counteract an externality of capital accumulation. The logic behind Jeske's argument is similar and he finds that capital controls may be welfare improving.
} 
The country can issue only one-period debt $\left(d_{t}\right)$. The price of debt is denoted $q_{t}$.

There is a continuum of risk-neutral lenders that, in equilibrium, lend to the country as long as the expected return on their assets is not lower than the risk-free interest rate in international markets, $r^{*}$. The price of a bond that delivers one unit of the good next period with certainty, $\left(1+r^{*}\right)^{-1}$, is denoted $q^{*}$. There is a maximum amount of debt the country can contract that prevents it from running Ponzi schemes but it is never reached in equilibrium.

The economy's flow budget constraint is then given by:

$$
c_{t}=\left\{\begin{array}{l}
y_{t}-d_{t}+q_{t} d_{t+1}, \text { if it has never defaulted } \\
(1-\gamma) y_{t}, \text { if it has ever defaulted }
\end{array}\right.
$$

In a stochastic world, the incentive compatible level of debt fluctuates. If debt goes above its incentive compatible level, the debtor prefers not to repay it, but then both creditors and debtors have incentives to renegotiate. I make the extreme assumption that the country can costlessly renegotiate its debt - there are no delays and no punishment.

There is a stochastic state variable $s$. At the beginning of the period, its value is revealed and the country makes decisions about debt and default. The country can:

- Repay its debt $d$;

- Default: in which case the output loss is incurred and the country loses access to international capital markets;

- Renegotiate: the debt becomes $a d$, where $a$ is the outcome of the bargaining process, as specified below. There is no punishment.

Using the flow budget constraint and the expressions for output, and denoting by $d^{F}$ the face value of debt to be repayed in the following period, the value functions associated with each option are:

$$
\begin{aligned}
V_{\text {pay }}(d, s) & =\max _{d^{\prime}}\left\{u\left(y-d+q\left(d^{F}, s\right) d^{F}\right)+\beta E\left[V\left(d^{F}, s^{\prime}\right)\right]\right\} \\
V_{d e f}(s) & =u((1-\gamma) y)+\beta V_{d e f}(s) \\
V_{\text {reneg }}(d, s) & =\max _{d^{\prime}}\left\{u\left(y-a d+q\left(d^{F}, s\right) d^{F}\right)+\beta E\left[V\left(d^{F}, s^{\prime}\right)\right]\right\}=V_{\text {pay }}(a d, s)
\end{aligned}
$$

where $d^{F}$ is the face value of debt and $q\left(d^{F}, s\right)$ is its unit price. The country chooses the maximum of them:

$$
V(d, s)=\max \left\{V_{\text {pay }}(d, s), V_{\text {pay }}(a d, s), V_{\text {def }}(s)\right\}
$$


The key difference between this and Yue (2010) is that the renegotiation process is costless and instantaneous. Following Yue (2010), $a$ is determined by a Nash bargaining game, where the outside option for the country is autarky and the outside option for the lenders is walking away with no repayment at all. Thus the surpluses for borrower and lenders are:

$$
\begin{aligned}
\Delta^{B}(a d, s) & =V_{\text {pay }}(a d, s)-V_{d e f}(s) \\
\Delta^{L}(a d, s) & =a d
\end{aligned}
$$

The level of debt after renegotiation, $\alpha(s) d$, is given by:

$$
\alpha(s) d=\arg \max _{a d}\left(\left[\Delta^{B}(a d, s)\right]^{\theta}\left[\Delta^{L}(a d, s)\right]^{1-\theta}\right)
$$

subject to

$$
\Delta^{B}(a d, s) \geq 0 \text { and } \Delta^{L}(a d, s) \geq 0
$$

As $a$ only appears multiplying $d$, the solution for $\alpha(s) d$ does not depend on $d$.

I assume $\theta=0$ : lenders have all the bargaining power in the renegotiation stage, so the borrower gets no surplus from the bargaining process. Most of the literature following Eaton and Gersovitz (1981) assumes that the borrower fully repays its debt provided it is incentive compatible to do so. As noted by Fernandez and Rosenthal (1990), that is equivalent to assuming that all bargaining power lies with the creditors (expost). Here, by assuming $\theta=0, \mathrm{I}$ am adding costless renegotiation and maintaining that assumption: creditors are able to extract the maximum incentive compatible payments from the borrower up to the face value of debt, $d^{F}$.

The recovery rate $\alpha(s)$ is given by:

$$
\Delta^{B}(\alpha(s) d, s)=0 \Longrightarrow V_{\text {pay }}(\alpha(s) d, s)=V_{\text {def }}(s)
$$

For $\theta=0, \alpha(s) d$ is the incentive compatible level of debt, beyond which greater debt would make the country prefer to default. ${ }^{12}$ Hence, the country is always indifferent between defaulting and renegotiating, and it is assumed it chooses the latter. ${ }^{13}$

As renegotiation is costless, at state $s$ lenders know they will receive at most $\alpha(s) d$, and borrowers will always repay their debt up to $\alpha(s) d$. If $d>\alpha(s) d$ for some state $s$, there is no cost for borrowers to convert their debt $d$ into $\alpha(s) d$. The possibility of costless renegotiation with $\theta=0$ makes debt contingent in a particular way: debt can be costlessly reduced to its incentive compatible level.

\footnotetext{
${ }^{12} V_{\text {pay }}$ is decreasing in the level of debt, and $V_{d e f}$ is independent of the level of debt. So $\alpha(s) d$ is the maximum value of debt such that $V_{\text {pay }}(\alpha(s) d, s) \geq V_{\text {def }}(s)$.

${ }^{13}$ Alternatively, I am assuming $\theta$ is larger than 0 , but very small.
} 
Higher values of $\theta$ would lead to larger reductions in debt. Owing to its barganing power, the borrower would obtain part of what lenders could lose in the renegotiation process (the full debt, $d$ ). In the extreme case of $\theta=1$, the borrower would have all the bargaining power and $\alpha(s)$ would be $0 .^{14}$

For simplicity, there are 2 possible states, $s_{t} \in\{h, l\}$, and the probability of switching states is $\psi \cdot \operatorname{Pr}\left(s_{t} \neq s_{t-1}\right)=\psi, \operatorname{Pr}\left(s_{t}=s_{t-1}\right)=1-\psi . \psi \leq 0.5$. Let $V^{h}(d)$ and $V^{l}(d)$ be value functions in the high and low states, respectively, and denote by $d^{h}$ and $d^{l}$ the incentive compatible level of debt in each state such that:

$$
V_{\text {pay }}^{h}\left(d^{h}\right)=V_{d e f}^{h} \quad, \quad V_{\text {pay }}^{l}\left(d^{l}\right)=V_{d e f}^{l}
$$

Assume WLOG $d^{h}>d^{l}$. If the face value of debt $d^{F}$ is smaller than $d^{l}$, debt is not contingent and there is no debt reduction in the following period. But if the country chooses $d^{F}$ such that $d^{l}<d^{F} \leq d^{h}$, debt repayments are de-facto contingent.

Consider $d^{F} \in\left(d^{l}, d^{h}\right]$. If $s^{\prime}=h$ then $d^{F}$ will be repayed; if $s^{\prime}=l$, repayment will be $d^{l}$ and debt reduction will be $\Delta d=d^{F}-d^{l}$. Denote the the expected repayment by $d^{\prime}$. If $s=h$, the expected repayment $d^{\prime}=(1-\psi) d^{F}+\psi d^{l}$. If $s=l$, the expected repayment $d^{\prime}=(1-\psi) d^{l}+\psi d^{F}$. Thus if $s=h$, repayments in the following period are given by $d^{F}=d^{\prime}+\psi \Delta d\left(\right.$ if $\left.s^{\prime}=h\right)$ and $d^{l}=d^{\prime}-(1-\psi) \Delta d$ (if $\left.s^{\prime}=h\right) \cdot{ }^{15}$

As lenders are risk neutral and competitive, equilibrium bond prices $q\left(d^{F}, s\right)$ are such that $q\left(d^{F}, s\right) d^{F}=q^{*} d^{\prime}$. Consider the case $s=h$ and $s^{\prime}=l$. Then, debt will be renegotiated and reduced. The "haircut" corresponds to the proportional fall in the level of debt, $\Delta d / d^{F}$. That is the key variable of the model. The spread over treasuries is the rate paid above the risk-free rate if there is no renegotiation, so it is the difference between the face value of debt $d^{F}$ and the expected repayment $d^{\prime}$, divided by $d^{F}$. Thus the spread over treasuries is $\psi \Delta d / d^{F}$ — the probability of renegotiation $(\psi)$ times the haircut.

Two stochastic versions of the model are considered: stochastic $r^{*}$ and stochastic $y$.

Throughout the paper, I make assumptions to ensure that the country exhausts its borrowing possibilities: it borrows $d^{F}=d^{h}$, making debt as high as possible in each possible state. In this section I will assume that $\beta$ is very low, as is typically assumed in the recent quantitative models of sovereign default. ${ }^{16}$ In Section 3 , the assumption of a very low $\beta$ is removed and replaced by the assumption of a high marginal productivity of capital. As in general $d^{F} \leq d^{h}$, the results in this paper can be seen as upper bounds

\footnotetext{
${ }^{14}$ As renegotiation is costless, if $\theta=1$ there would be no borrowing in equilibrium. A model with $\theta=1$ requires some costs for renegotiating debt.

${ }^{15}$ Likewise, if $s=l$, repayments in the following period are $d^{l}=d^{\prime}-\psi \Delta d$ (if $s^{\prime}=l$ ) and $d^{F}=d^{\prime}+(1-\psi) \Delta d\left(\right.$ if $\left.s^{\prime}=h\right)$.

${ }^{16}$ Arellano (2008) uses $\beta=0.82$ /year, Aguiar and Gopinath (2006) and Yue (2010) use lower values. Such extreme impatience is often interpreted as the discount rate of the policy maker, different from the population.
} 
for debt delief following a negative shock, under the assumption that the renegotiation process generates no further reductions in debt.

\subsection{Stochastic world interest rates}

Here, I analyse the contingent debt contract for an economy with fixed per-period endowment, but fluctuations in world interest rates, $r^{*}$, leading to fluctuations in the price of risk-free debt, $q^{*}$. The price of a riskless bond in international markets is $q^{* h}$ in the high state and $q^{* l}$ in the low state, $q^{* h}>q^{* l}$.

In equilibrium bond prices are such that $q\left(d^{F}, s\right) d^{F}=q^{* h} d^{\prime}$ in the high state and $q\left(d^{F}, s\right) d^{F}=q^{* l} d^{\prime}$ in the low state. If $d^{F}<d^{l}$, the value functions conditional on repayment are:

$$
\begin{aligned}
V_{\text {pay }}^{h}(d) & =\max _{d^{F}}\left\{u\left(y-d+q^{* h} d^{F}\right)+\beta\left[(1-\psi) V_{\text {pay }}^{h}\left(d^{F}\right)+\psi V_{\text {pay }}^{l}\left(d^{F}\right)\right]\right\} \\
V_{\text {pay }}^{l}(d) & =\max _{d^{F}}\left\{u\left(y-d+q^{* l} d^{F}\right)+\beta\left[(1-\psi) V_{\text {pay }}^{l}\left(d^{F}\right)+\psi V_{\text {pay }}^{h}\left(d^{F}\right)\right]\right\}
\end{aligned}
$$

If $d^{F} \in\left(d^{l}, d^{h}\right]$, the value functions conditional on repayment are:

$$
\begin{aligned}
V_{\text {pay }}^{h}(d) & =\max _{d^{F}}\left\{u\left(y-d+q^{* h}\left[(1-\psi) d^{F}+\psi d^{l}\right]\right)+\beta\left[(1-\psi) V_{\text {pay }}^{h}\left(d^{F}\right)+\psi V_{\text {pay }}^{l}\left(d^{l}\right)\right]\right\} \\
V_{\text {pay }}^{l}(d) & =\max _{d^{F}}\left\{u\left(y-d+q^{* l}\left[(1-\psi) d^{l}+\psi d^{F}\right]\right)+\beta\left[(1-\psi) V_{\text {pay }}^{l}\left(d^{l}\right)+\psi V_{\text {pay }}^{h}\left(d^{F}\right)\right]\right\}
\end{aligned}
$$

The value functions in the following period are those associated with repayment and the level of debt is adjusted to its incentive compatible level.

In case of default, the value function in both states is:

$$
V_{d e f}=u((1-\gamma) y)+\beta V_{d e f}=\frac{u((1-\gamma) y)}{1-\beta}
$$

It makes no difference whether foreign interest rates are low or high if the country is excluded from international financial markets.

I assume $\beta<q^{* l}$, which implies that the country will choose to borrow and, if possible, increase current consumption at expense of future consumption. I focus on the "steady state" of the model, where consumption might depend on the state, but does not depend on time.

Proposition 1 If $\beta<q^{* l}$, an equilibrium with $c_{t}^{h}=c^{h}$ and $c_{t}^{l}=c^{l}$ for all $t$ and some constants $c^{h}$ and $c^{l}$ such that $c^{h} \geq c^{l}$ implies that the country always borrows as much as it can, $d^{F}=d^{h}$ in all periods and states.

Proof. See appendix. 
As the country is borrowing as much as it can, the country's debt is equal to its incentive compatible level in each future state: debt payment is $d^{h}$ if $s^{\prime}=h$ and $d^{l}$ if $s^{\prime}=l$ - which is equivalent to what they would be in a world with complete contingent contracts but no commitment to repay.

As the value function in case of default does not depend on the state, $V_{\text {pay }}^{h}\left(d^{h}\right)=V_{\text {def }}=$ $V_{\text {pay }}^{l}\left(d^{l}\right)$. Consequently, consumption is given by:

$$
c^{h}=c^{l}=(1-\gamma) y
$$

Denote $\bar{q}=\left(q^{* h}+q^{* l}\right) / 2$. The following proposition establishes the value of $\Delta d$ :

Proposition 2 If $d^{F}=d^{h}$ in all periods and states, $\Delta d$ is given by:

$$
\frac{d^{h}-d^{l}}{d^{h}}=\frac{q^{* h}-q^{* l}}{1-q^{* l}+2 \psi \bar{q}} \quad, \quad \frac{d^{h}-d^{l}}{d^{l}}=\frac{q^{* h}-q^{* l}}{1-q^{* h}+2 \psi \bar{q}}
$$

Proof. As $d^{F}=d^{h}$ and $V_{\text {pay }}^{h}\left(d^{h}\right)=V_{d e f}=V_{\text {pay }}^{l}\left(d^{l}\right)$, the value functions in the high and low states are:

$$
\begin{aligned}
V_{\text {pay }}^{h}\left(d^{h}\right) & =u\left(y-d^{h}+q^{* h}\left[(1-\psi) d^{h}+\psi d^{l}\right]\right)+\beta V_{\text {def }} \\
V_{\text {pay }}^{l}\left(d^{l}\right) & =u\left(y-d^{l}+q^{* l}\left[(1-\psi) d^{l}+\psi d^{h}\right]\right)+\beta V_{\text {def }}
\end{aligned}
$$

so $V_{\text {pay }}^{h}\left(d^{h}\right)=V_{\text {pay }}^{l}\left(d^{l}\right)$ implies:

$$
y-d^{h}+q^{* h}\left[(1-\psi) d^{h}+\psi d^{l}\right]=y-d^{l}+q^{* l}\left[(1-\psi) d^{l}+\psi d^{h}\right]
$$

which yields the claim.

Debt relief depends on: (i) the magnitude of interest rate fluctuations and (ii) the persistence of the interest rate process. In the i.i.d. case, $\psi=0.5$, debt relief when the state switches from $h$ to $l$ is approximately equal to $\left(q^{* h}-q^{* l}\right)$. In the other extreme, as $\psi \rightarrow 0$, debt reduction is much higher: $\left(q^{* h}-q^{* l}\right) /\left(1-q^{* l}\right)$, as it has to compensate for all the expected future loss brought on by the fall in $q^{*}$. Hence, higher persistence implies higher difference between $d^{h}$ and $d^{l}$.

The output cost $\gamma$ has no effect on $\Delta d / d$. It is important to determine the level of $d$, but it does not influence the ratio between the incentive compatible levels of debt in both states.

\subsection{Stochastic endowment}

In this section, I fix the world interest rates at $r^{*}$ and allow $y$ to fluctuate between $y^{h}$ in the high state and $y^{l}$ in the low state, $y^{h}>y^{l}$. 
If $d^{F} \in\left(d^{l}, d^{h}\right]$, the value functions conditional on repayment are:

$$
\begin{aligned}
V_{\text {pay }}^{h}(d) & =\max _{d^{F}}\left\{u\left(y^{h}-d+q^{*}\left[(1-\psi) d^{F}+\psi d^{l}\right]\right)+\beta\left[(1-\psi) V^{h}\left(d^{F}\right)+\psi V^{l}\left(d^{l}\right)\right]\right\} \\
V_{p a y}^{l}(d) & =\max _{d^{F}}\left\{u\left(y^{l}-d+q^{*}\left[(1-\psi) d^{l}+\psi d^{F}\right]\right)+\beta\left[(1-\psi) V^{l}\left(d^{l}\right)+\psi V^{h}\left(d^{F}\right)\right]\right\}
\end{aligned}
$$

Should the country go into default, the value functions are:

$$
\begin{aligned}
V_{\text {def }}^{h} & =u\left((1-\gamma) y^{h}\right)+\beta\left[(1-\psi) V_{\text {def }}^{h}+\psi V_{\text {def }}^{l}\right] \\
V_{\text {def }}^{l} & =u\left((1-\gamma) y^{l}\right)+\beta\left[(1-\psi) V_{\text {def }}^{l}+\psi V_{\text {def }}^{h}\right]
\end{aligned}
$$

I assume $\beta<q^{* l}$. An argument identical to Proposition 1 shows that in the "steady state" of the model, the country exhausts its borrowing possibilities, choosing $d^{F}=d^{h}$ in all states and periods.

The following proposition establishes the value of $\Delta d$ :

Proposition 3 If $d^{F}=d^{h}$ in all periods and states, $\Delta d$ is given by:

$$
\frac{d^{h}-d^{l}}{\bar{d}}=\frac{\left(1-q^{*}\right)}{1-q^{*}(1-2 \psi)} \frac{y^{h}-y^{l}}{\bar{y}}
$$

where $\bar{d}=\left(d^{h}+d^{l}\right) / 2$ and $\bar{y}=\left(y^{h}+y^{l}\right) / 2$.

Proof. Consider the case $y=y^{h}$. If the borrowing constraint is binding and debt is at its maximum level, then:

$$
V_{\text {pay }}^{h}\left(d^{h}\right)=u\left(y^{h}-d^{h}+q^{*}\left[\psi d^{l}+(1-\psi) d^{h}\right]\right)+\beta\left[(1-\psi) V_{d e f}^{h}+\psi V_{d e f}^{l}\right]
$$

Making $V_{\text {pay }}^{h}\left(d^{h}\right)=V_{d e f}^{h}$, we get:

$$
d^{h}-q^{*}\left[\psi d^{l}+(1-\psi) d^{h}\right]=\gamma y^{h}
$$

Analogously:

$$
d^{l}-q^{*}\left[\psi d^{h}+(1-\psi) d^{l}\right]=\gamma y^{l}
$$

Subtracting (4) from (3), we get:

$$
\left(d^{h}-d^{l}\right)\left[1-q^{*}(1-2 \psi)\right]=\gamma\left(y^{h}-y^{l}\right)
$$

Summing (4) and (3) and manipulating, we get:

$$
\gamma=\frac{\bar{d}}{\bar{y}}\left(1-q^{*}\right)
$$

Substituting the value of $\gamma$ in (5), we get the claim.

As before, larger fluctuations and more persistent states imply higher debt relief and $\gamma$ has no effect on $\Delta d / \bar{d}$. 


\subsection{Contrasting stochastic $q^{*}$ and stochastic $y$}

In order to contrast debt relief in the cases of stochastic interest rates and endowments, we need to contrast the numerators of Equations (1) and (2), as the denominators are virtually the same. The key distinction is that the numerator of Equation 1 is the difference between interest rates in both states, while the numerator of Equation 2 is the relative change in endowment multiplied by $\left(1-q^{*}\right)$, the present discounted interest rate. A reasonable range for the numerator of Equation 1 (stochastic interest rates) is between $2 \%$ and $4 \%$. On the other hand, a reasonable range for endowment fluctuations is from $2 \%$ to, say, $7 \%$, which in combination with a range of average real interest rates from $1 \%$ to $3 \%$ gives a range for the numerator of Equation 2 (stochastic technology) of $0.02 \%$ to $0.2 \%$. This is one or two orders of magnitude below what we get from fluctuations in world interest rates.

Even permanent fluctuations in output would not generate sizable debt relief. The effect of a permanent output fall on debt relief can be found by taking the limit $\psi \rightarrow 0$. In that case, we get

$$
\frac{d^{h}-d^{l}}{\bar{d}}=\frac{y^{h}-y^{l}}{\bar{y}}
$$

so a permanent $2 \%$ fall in output leads to a fall of $2 \%$ in the incentive compatible level of debt.

Fluctuations in $q^{*}$ alter the cost of servicing debt. Shocks to $y$ change the present value of output losses due to default. Both these changes affect the incentive compatible level of debt. However, there is a great distinction in quantitative effects of shocks to $y$ and $q^{*}$.

Shocks to $y$ affect the economy regardless of the decision on default. Defaulting on debt does not solve the problem, does not increase the endowment. Low output increases the incentives for default only because the punishment for default is assumed to be proportional to output. Therefore, in order to generate a fall in the incentive compatible level of debt of $x \%$, the expected present value of output (considering the present and all future periods) needs to decline by $x \%$. But that cannot be more than a couple of percentage points. ${ }^{17}$

On the other hand, if the country decides not to repay and stops interacting with world financial markets, $q^{*}$ has no effect in the economy. In this sense, default "solves" the problem of high interest rates. As an illustration, if the country finds incentive

\footnotetext{
${ }^{17}$ In Aguiar and Gopinath (2006) and Yue (2010), the loss of ouput in autarky is multiplicative, exactly like here. Productivity shocks may lead to larger changes in the incentive compatible level of debt if the costs of defaulting are smaller at the low state. That is an implicit assumption in Arellano (2008). However, if that is the case, fluctuations in the cost of defaulting are playing the main role - not fluctuations in output - and a better understanding of the costs of defaulting is needed before we can accept productivity shocks as important drivers of default.
} 
compatible to repay $\$ 1$ a year, at a permanent interest rate of $1 \%$ this implies the country can sustain a debt of $\$ 100$. If interest rates are constant and equal to $2 \%$, that implies an incentive compatible level of debt of $\$ 50$. How large is the debt reduction generated by observed shocks to world interest rates? Section 4 provides the answer in the case of the large interest rate hikes of the early 1980's.

In general, the results of this paper point to the importance of shocks that have large impacts in the economy only (or mostly) if the country chooses to keep interacting with world financial markets or only (or mostly) if the country chooses to default on its debt. By affecting only $V_{\text {pay }}$ or only $V_{d e f}$, those shocks provide larger incentives to "switch to the other value function".

In the model of sovereign default and debt renegotiation in Yue (2010), the recovery rate depends on the bargaining power of the borrower, $\theta \in[0,1]$. As in this paper, if $\theta=1$, the haircut is $100 \%$, by construction. This paper corresponds to the case $\theta=0$, the haircut is given solely by the fall in the incentive compatible level of debt, which is close to 0 in the case of an output shock. Yue (2010) uses $\theta=0.72$, which means that the borrower gets $72 \%$ of the total surplus and, indeed, the obtained haircut is $73 \%$. That does not seem inconsistent with a very small fall in the incentive compatible level of debt. But if the bulk of the debt reduction is due to the bargaining process, any shock that generates a fall of a few percentage points in the incentive compatible level of debt would also lead to a large debt reduction.

\section{Debt and default in a growth model}

In this Section, I introduce capital accumulation in the model. The domestic country borrows because its marginal product of capital is higher, not because of risk sharing or impatience. The assumption of a low $\beta$ is replaced with $\beta=q^{*}$. In the case of stochastic world interest rates, $q^{*}$ fluctuates around $\beta$.

The main conclusion is that the impact of output and interest-rate shocks on the incentive compatible level of debt are very similar to their impact in the endowment economy.

The model follows the structure of the previous section, but with capital, $k_{t}$, depreciating at rate $\delta$ and output a function solely of the level of capital, as labour is normalised to 1:

$$
y_{t}=\left\{\begin{array}{c}
A_{t} \cdot f\left(k_{t}\right), \text { if it has never defaulted } \\
A_{t}(1-\gamma) \cdot f\left(k_{t}\right), \text { if it has ever defaulted }
\end{array}\right.
$$


The economy's flow budget constraint is then given by:

$$
c_{t}+k_{t+1}=\left\{\begin{array}{c}
A_{t} \cdot f\left(k_{t}\right)+(1-\delta) k_{t}-d_{t}+q_{t} d_{t+1}, \text { if it has never defaulted } \\
A_{t}(1-\gamma) \cdot f\left(k_{t}\right)+(1-\delta) k_{t}, \text { if it has ever defaulted }
\end{array}\right.
$$

\subsection{Deterministic Model}

The deterministic version of the model with capital accumulation serves two purposes: it sheds light on the relationship between growth and capital flows, and helps to understand the results of the stochastic model. ${ }^{18}$

The value functions of the deterministic model are given by:

$$
V(k, d)=\max \left\{V_{\text {pay }}(k, d), V_{\text {def }}(k, \gamma)\right\}
$$

and:

$$
\begin{aligned}
V_{\text {pay }}(k, d) & =\max _{k^{\prime}, d^{\prime}}\left\{u\left(A f(k)+(1-\delta) k-k^{\prime}-d+q d^{\prime}\right)+\beta V\left(k^{\prime}, d^{\prime}\right)\right\} \\
V_{\text {def }}(k, \gamma) & =\max _{k^{\prime}}\left\{u\left((1-\gamma) A f(k)+(1-\delta) k-k^{\prime}\right)+\beta V_{\text {def }}\left(k^{\prime}\right)\right\}
\end{aligned}
$$

I assume that decisions about $k^{\prime}$ and $d^{\prime}$ are made simultaneously and lenders can observe $k^{\prime}$ before taking their lending decisions (or condition their decisions on $k^{\prime}$ ). As noted by Cohen and Sachs (1986), the country would otherwise have an incentive to borrow $d^{\prime}$ but then invest less, consume more and default on its debt. ${ }^{19}$

The following results hold in an equilibrium with no uncertainty:

1. $q=q^{*}$, a constant. As there is no uncertainty, $q=q^{*}$ if the country will repay and $q=0$ otherwise. The choice $d^{\prime}=0$ is strictly better than any choice $d^{\prime}$ such that $q=0$ because that yields the same amount of consumption today and more production next period (by avoiding the $\gamma A f(k)$ output loss). The no-default condition is $V_{\text {pay }}(k, d) \geq$ $V_{\text {def }}(k, \gamma)$.

\footnotetext{
${ }^{18}$ The study of external debt and default is closely related to the question of why capital does not flow from rich to poor countries. One proposed explanation is that the risk of default prevents larger capital inflows in emerging economies (Reinhart and Rogoff (2004) and Reinhart, Rogoff and Savastano (2003)). Alternative explanations emphasise differences in productivity (Lucas (1990)) and question whether the marginal productivity of capital is really higher in poor countries (Caselli and Feyrer (2007)). Yet, most of the recent work on debt and default building on Eaton and Gersovitz (1981) focuses on risk sharing. Cohen and Sachs (1986) present a growth model in which debt is repaid only if it is incentive compatible to do so, but assume a linear production function and have no uncertainty. They also analyse a numerical example with decreasing returns to capital which is essentially the deterministic model of this section. Marcet and Marimon (1992) and Kehoe and Perri (2004) also study economies with capital accumulation.

${ }^{19}$ To see this, note that in the optimal plan $V_{\text {pay }}\left(k^{\prime}, d^{\prime}\right)=V_{d e f}\left(k^{\prime}, \gamma\right)$ and $u^{\prime}(c)=\beta \frac{\partial V_{\text {pay }}}{\partial k^{\prime}}\left(k^{\prime}, d^{\prime}\right)$. But $\frac{\partial V_{\text {pay }}}{\partial k^{\prime}}\left(k^{\prime}, d^{\prime}\right)>$ $\frac{\partial V_{d e f}}{\partial k^{\prime}}\left(k^{\prime}\right)$, so if the country has already borrowed $d^{\prime}$ and hasn't committed to $k^{\prime}$, a marginal decrease in $k^{\prime}$ leads to an increase in today's utility that is bigger than the decrease in tomorrow's value. This type of moral hazard problem is studied by Atkeson (1991).
} 
2. $d^{\max }(k, \gamma)$ is the maximum level of incentive compatible debt and is increasing in $\gamma$. Since by differentiating the value function we obtain that $V_{\text {pay }}$ is decreasing in $d$ and $V_{\text {def }}$ is decreasing in $\gamma, V_{\text {pay }}\left(k, d^{\max }\right)=V_{\text {def }}(k, \gamma)$. Thus, an increase in $\gamma$ implies an increase in $d^{\max }(k, \gamma)$.

3. If $k^{\prime}$ is below the steady state level of capital, $k^{*}$, then $d^{\prime}=d^{\max }$. In the steady state, $k^{\prime}=k=k^{*}$ and the marginal productivity of capital, $m p k=A f^{\prime}\left(k^{*}\right)-\delta$, equals the marginal cost of renting an extra unit of capital, $r^{*}$. In this case, the country has no incentive to change the level of its debt, because capital is at the optimal level and smooth consumption can be achieved by always choosing $d^{\prime}=d$. In contrast, if $k<k^{*}, m p k>r^{*}$ and $d$ cannot be smaller than $d^{\max }$, otherwise the no-default condition would not bind, so the country could borrow an extra unit at $r^{*}$, invest it and obtain a greater return than $r^{*}$ next period.

4. If $\gamma=0$, no debt can be sustained. If $\gamma=0$, any positive discounted stream of repayment is worse than defaulting, so the maximum incentive compatible positive discounted stream of repayment is zero. ${ }^{20}$

5. If $\gamma=1$, we obtain full commitment. If $\gamma=1$ with no default, in the steady state, the country obtains consumption equal to $A f\left(k^{*}\right)-\delta k^{*}-r^{*} d^{*}$ which is positive because $d^{*} \leq k^{*}, A f^{\prime}\left(k^{*}\right)-\delta=r^{*}$ and $f\left(k^{*}\right)>k^{*} f^{\prime}\left(k^{*}\right)$. Hence the first best, full commitment equilibrium is incentive compatible.

Using these results, I now derive the path of debt in the neighbourhood of $\gamma=0$. I will detail two observations that are used to derive it.

First, consider $k_{p}^{\prime}$ and $d^{\prime}$ such that $V_{\text {pay }}\left(k_{p}^{\prime}, d^{\prime}\right)=V_{\text {def }}\left(k_{p}^{\prime}, \gamma\right)$ and $k_{p}^{\prime} \leq k^{*}$. Then there exists some $k \leq k_{p}^{\prime}$ and $d$ such that the country is indifferent between "repaying and choosing $\left(k_{p}^{\prime}, d^{\prime}\right)$ " and "defaulting and choosing $\left(k_{d}^{\prime}\right)$ ". The value functions will be equivalent in this case and are given by:

$$
\begin{aligned}
V_{\text {pay }}(k, d) & =\max _{k_{p}^{\prime}, d^{\prime}}\left\{u\left(y+(1-\delta) k-k_{p}^{\prime}-d+q d^{\prime}\right)+\beta V_{\text {pay }}\left(k_{p}^{\prime}, d^{\prime}\right)\right\} \\
V_{\text {def }}(k, \gamma) & =\max _{k_{d}^{\prime}}\left\{u\left((1-\gamma) y+(1-\delta) k-k_{d}^{\prime}\right)+\beta V_{\text {def }}\left(k_{d}^{\prime}, \gamma\right)\right\}
\end{aligned}
$$

Second, from result 4 , we know that the value functions when $\gamma=d=d^{\prime}=0$ are

\footnotetext{
${ }^{20}$ This result is due to the absence of uncertainty in the model. It has already been shown in the literature that, with uncertainty, there may be debt in equilibrium even in the absence of output costs (Eaton and Gersovitz, 1981).
} 
identical and have a common optimal level of capital:

$$
\begin{aligned}
V_{0}(k) & =\max _{k^{\prime}}\left\{u\left(y+(1-\delta) k-k^{\prime}\right)+\beta V_{\text {def }}\left(k^{\prime}, 0\right)\right\} \\
& =\max _{k^{\prime}}\left\{u\left(y+(1-\delta) k-k^{\prime}\right)+\beta V_{\text {pay }}\left(k^{\prime}, 0\right)\right\}
\end{aligned}
$$

Then, from result 3 , we always have $d^{\prime}=d^{\max }$ and therefore the no default condition will always bind: $V_{\text {pay }}\left(k, d^{\max }\right)=V_{\text {def }}(k, \gamma)$. Using the first observation, we rewrite these value functions in the form above. Then by taking a linear approximation of $V_{\text {pay }}(k, d)$ and $V_{d e f}(k, \gamma)$ around $V_{0}(k)$ and manipulating the linearised expressions, we can find $d$ and $\gamma$ that equate $V_{\text {pay }}(k, d)$ and $V_{\text {def }}(k, \gamma)$ without solving for the value functions. The expression for $d$ turns out to be a good approximation for its true value if $\gamma$ is not more than a few percentage points. This is because when $\gamma \rightarrow 0$, the optimal choice of capital is independent of the decision about defaulting - which allows us to get the analytical results. As $\gamma$ moves away from 0 , that is no longer true, however the impact on the value function of reoptimising the level of capital due to a $1 \%$ or $2 \%$ fall in productivity is very small, and so is its impact on the maximum incentive compatible level of debt.

The results do not depend on the functional forms of utility or production, which have only second order effects.

Proposition 4 In this economy, for a very small $\gamma$ :

1. In steady state:

$$
d^{*}=\frac{\gamma y^{*}}{1-q^{*}}
$$

2. For $y_{t}<y^{*}$ :

$$
\frac{d_{t+1}}{y_{t}}=\frac{\gamma}{1-q}+\frac{\Delta d_{t+1}}{(1-q) y_{t}}
$$

and:

$$
d_{t}=q \cdot d_{t+1}+(1-q) \frac{\gamma y_{t}}{1-q}
$$

Proof. See appendix.

Part (1) of the proposition shows that in the steady state, the country keeps repaying its debt if the interest payment, $d^{*}\left(1-q^{*}\right)$, is not greater than the output loss, $\gamma y^{*}$, due to default. The debt as proportion of GDP is, to a first order approximation, equal to $\gamma /\left(1-q^{*}\right)$. Positive debt with no uncertainty arises in equilibrium to finance convergence. If $\gamma=1 \%$ and $q^{*}=0.98\left(r^{*} \approx 2 \%\right)$, the debt-GDP ratio is $50 \%$.

The level of debt is proportional to the output loss and inversely proportional to the risk-free interest rate. Note that a change in interest rate from $1 \%$ to $2 \%$ has the same 
impact on $d$ as a $50 \%$ decrease in GDP. The intuition for the different impacts of $A$ and $q^{*}$ on the incentive compatible level of debt (Equation 6) is similar to the reasons for their distinct effects of shocks in Section 2 (Equations 1 and 2).

Part (2) of the proposition shows that for $y_{t}<y^{*}$, the condition for default reduces to a comparison between output losses and resources paid to foreign agents in the present period. But the increase in debt is endogenously determined by considering that the country will be indifferent in the next period between repaying and defaulting — so, ultimately, debt at period $t$ is obtained by backward induction from the steady state level of debt.

For $y_{t}<y^{*}$, the absolute level of debt is increasing over time because the present value of the output loss due to default is increasing as output rises to its steady state level. The debt-GDP ratio is decreasing over time, because positive capital inflows generate greater incentive for the country to repay, and capital inflows are decreasing over time.

The proposition also shows that in equilibrium the country must experience net outflows of resources on the path of convergence. Debt is increasing (financial account is in surplus) but the increase is smaller than the interest paid on its debt. So, even though the current account is in deficit, the country is a net exporter of goods.

In the appendix, I present a numerical example that confirms the analytical expression is a good approximation for the results and illustrates convergence in this economy.

\subsection{Stochastic world interest rates}

Here, I analyse an economy with fixed technology, $A$, and fluctuations in world interest rates, $r^{*}$, which lead to fluctuations in the price of risk-free debt, $q^{*}$. Except for capital accumulation and the assumption that $q^{* h}$ and $q^{* l}$ are close to $\beta$, the model is identical to that of section 2.1 .

As in section 2, renegotiation restores debt to its incentive compatible level. Denote by $d^{h}$ and $d^{l}$ the incentive compatible level of debt in the high and low states, respectively, such that $V_{\text {pay }}^{h}\left(k, d^{h}\right)=V_{d e f}^{h}(k)$ and $V_{\text {pay }}^{l}\left(d^{l}, k\right)=V_{d e f}^{l}(k)$. If the face value of debt $d^{F} \leq d^{l}$, the value functions are:

$$
\begin{aligned}
V_{\text {pay }}^{h}(k, d) & =\max _{k^{\prime}, d^{F}}\left\{u\left(c^{h}\right)+\beta\left[(1-\psi) V_{\text {pay }}^{h}\left(k^{\prime}, d^{F}\right)+\psi V_{\text {pay }}^{l}\left(k^{\prime}, d^{F}\right)\right]\right\} \\
V_{\text {pay }}^{l}(k, d) & =\max _{k^{\prime}, d^{F}}\left\{u\left(c^{l}\right)+\beta\left[(1-\psi) V_{\text {pay }}^{l}\left(k^{\prime}, d^{F}\right)+\psi V_{\text {pay }}^{h}\left(k^{\prime}, d^{F}\right)\right]\right\}
\end{aligned}
$$

where $c^{i}=A f(k)+(1-\delta) k-k^{\prime}-d+q^{* i} d^{F}$ for $i \in\{l, h\}$.

If $d^{F} \in\left(d^{l}, d^{h}\right]$, then $d^{l}$ is repayed if $s^{\prime}=l$ and $d^{F}$ is repayed if $s^{\prime}=h$. The value 
functions associated with repayment are:

$$
\begin{aligned}
V_{\text {pay }}^{h}(k, d) & =\max _{k^{\prime}, d^{F}}\left\{u\left(c^{h}\right)+\beta\left[(1-\psi) V_{\text {pay }}^{h}\left(k^{\prime}, d^{F}\right)+\psi V_{\text {pay }}^{l}\left(k^{\prime}, d^{l}\right)\right]\right\} \\
V_{\text {pay }}^{l}(k, d) & =\max _{k^{\prime}, d^{F}}\left\{u\left(c^{l}\right)+\beta\left[(1-\psi) V_{\text {pay }}^{l}\left(k^{\prime}, d^{l}\right)+\psi V_{\text {pay }}^{h}\left(k^{\prime}, d^{F}\right)\right]\right\}
\end{aligned}
$$

where $c^{h}=A f(k)+(1-\delta) k-k^{\prime}-d+q^{* h}\left[(1-\psi) d^{F}+\psi d^{l}\right]$ and $c^{l}=A f(k)+(1-$ $\delta) k-k^{\prime}-d+q^{* l}\left[(1-\psi) d^{l}+\psi d^{F}\right]$.

In the event of default, the value function in both states is:

$$
V_{d e f}(k, \gamma)=\max _{k^{\prime}}\left\{u\left((1-\gamma) A f(k)+(1-\delta) k-k^{\prime}\right)+\beta V_{d e f}\left(k^{\prime}, \gamma\right)\right\}
$$

Define $m p k=A f^{\prime}\left(k^{\prime}\right)-\delta$ and $r^{* i}=1 / q^{* i}-1$. If the marginal productivity of capital $m p k$ is larger that the interest rates and $q^{* h}$ and $q^{* l}$ are arbitrarily close to $\beta$, then the country borrows as much as it can, the face value of debt $d^{F}$ is $d^{h}$. The next proposition formalizes that.

Proposition 5 If $m p k>r^{* i}, q^{* h}-q^{* l}$ is arbitrarily small, and $q^{* h}$ and $q^{* l}$ are arbitrarily close to $\beta$, then $d^{F}=d^{h}$.

Proof. See appendix.

If the country's borrowing constraint is binding, $\Delta d=d^{h}-d^{l}$. In order to expand its borrowing possibilities, a country with a high marginal productivity of capital chooses to make debt in each of the future states as high as possible, respecting the incentive compatibility constraints. Debt repayment in each state, $d^{h}$ and $d^{l}$, are such that $V_{\text {pay }}^{h}\left(k, d^{h}\right)=V_{\text {pay }}^{l}\left(k, d^{l}\right)=V_{\text {def }}(k)$.

When the borrowing constraint is binding, the problem of the country is analogous to choosing debt in each state $d^{h}$ and $d^{l}$ - or to choosing the expected debt repayment $d^{\prime}$ and debt reduction $\Delta d-$ subject to incentive compatibility constraints.

\subsubsection{The value of $\Delta d$}

For analytical convenience, I consider that $d q^{*}=q^{* h}-q^{* l}$ is sufficiently small and work with linear approximations, which implies we are not considering the effects on the value function of reoptimising the choice of $k^{\prime}$ when the country changes state.

In addition, I temporarily consider an alternative process for $q^{*}$ that I denote by the $\xi$-process, as opposed to the $\psi$-process that we described above. At time $t=0, q_{0}^{*}=q^{* \xi}$; from time $t=1$ on, there is a constant probability at each period that $q^{*}$ permanently goes to $\bar{q}$. So, for $t>0$ : 
- if $q_{t-1}^{*}=q^{* \xi}, \operatorname{Pr}\left(q_{t}^{*}=q^{* \xi}\right)=\xi$ and $\operatorname{Pr}\left(q_{t}^{*}=\bar{q}\right)=1-\xi$;

- if $q_{t-1}^{*}=\bar{q}, q_{t}^{*}=\bar{q}$.

The value function at $(k, d)$ if $q_{t}=q^{* \xi}$ is:

$$
V^{\xi}\left(k, d, q^{* \xi}\right)=\max _{k^{\prime}, d^{\prime}, d^{\prime \xi}}\left\{u(c)+\beta\left[(1-\xi) V^{\operatorname{det}}\left(k^{\prime}, d^{\prime}\right)+\xi V^{\xi}\left(k^{\prime}, d^{\prime \xi}, q^{* \xi}\right)\right]\right\}
$$

where $c=A f(k)+(1-\delta) k-k^{\prime}-d+q^{* \xi}\left(d^{\prime}(1-\xi)+\xi d^{\prime \xi}\right)$ and $V^{\text {det }}$ is the value function in the model with no uncertainty.

The $\xi$-process and the $\psi$-process are related using the following lemma:

Lemma 6 Define $\bar{q}=\left(q^{* h}+q^{* l}\right) / 2$ and denote by $V^{h}\left(k, d, q^{* h}\right)$ the value function for the $\psi$-process. Then $V^{h}\left(k, d, q^{* h}\right)=V^{\xi}\left(k, d, q^{* h}\right)$ if $\xi=1-2 \psi$.

Proof. See appendix.

Compare the following two cases when $q^{*}$ follows the $\xi$-process: (1) $q^{*}=q^{* \xi}$ and debt is $d_{0}^{\xi}$ and (2) $q^{*}=\bar{q}$ and debt is $d_{0}$. We want to find the values of $d_{0}^{\xi}$ and $d_{0}$ that make the country indifferent between both cases in order to determine $\Delta d$ using proposition 5. By taking a linear approximation of $V^{\xi}\left(k, d^{\xi}, q^{* \xi}\right)$ around $V^{\operatorname{det}}\left(k, d_{0}\right)$ and using the indifference condition that $V^{\xi}\left(k, d^{\xi}, q^{* \xi}\right)=V^{\operatorname{det}}\left(k, d_{0}\right)$, we get the following lemma:

Lemma 7 Indifference between both states, $V^{\xi}\left(k, d^{\xi}, q^{* \xi}\right)=V^{\operatorname{det}}\left(k, d_{0}\right)$, implies:

$$
\begin{aligned}
& u^{\prime}\left(c_{0}\right)\left(d_{0}^{\xi}-d_{0}\right) \\
= & \sum_{t=0}^{\infty}(\beta \xi)^{t} u^{\prime}\left(c_{t}\right)\left(q^{* \xi}-\bar{q}\right) d_{t+1}+\sum_{t=0}^{\infty}(\beta \xi)^{t}\left[u^{\prime}\left(c_{t}\right) \bar{q}+\beta \frac{\partial V\left(k_{t+1}, d_{t+1}\right)}{\partial d}\right]\left(d_{t+1}^{\xi}-d_{t+1}\right)
\end{aligned}
$$

where $d_{t+1}^{\xi}$ is debt contracted at time $t$ if $q_{t}^{*}=q^{* \xi}$ and $d_{t+1}$ is debt contracted at time $t$ if $q_{t}^{*}=\bar{q}$.

Proof. See appendix.

Suppose that $q^{* \xi}>\bar{q}$. The first line in the above expression shows the utility cost of having higher debt. The second line shows the utility benefit of borrowing at a lower rate, taking into account the probability of cheaper borrowing in future periods, plus the benefit of being able to borrow more due to lower interest rates. If the borrowing constraint is binding, then

$$
u^{\prime}\left(c_{t}\right) \bar{q}>-\beta \frac{\partial V\left(k_{t+1}, d_{t+1}\right)}{\partial d}
$$


which means that the benefit of borrowing an extra unit this period is greater than the cost of holding an extra unit of debt next period.

From Lemma 7, we can write:

$$
\frac{d_{0}^{\xi}-d_{0}}{d_{0}}>\sum_{t=0}^{\infty}(\beta \xi)^{t} \frac{u^{\prime}\left(c_{t}\right)}{u^{\prime}\left(c_{0}\right)}\left(q^{\xi}-\bar{q}\right) \frac{d_{t+1}}{d_{0}}
$$

It is convenient to consider Equation 7 as we approach the steady state of the deterministic economy. Formally, first I take the limit of small shocks $\left(q^{* h}-q^{* l} \rightarrow 0^{+}\right)$and then I consider the limit of small differences in the marginal product of capital $\left(m p k-r^{*} \rightarrow 0^{+}\right)$.

In the limit of small shocks, as $k$ approaches $k^{*}$, the borrowing constraint stops binding, $c_{t}$ and $d_{t}$ approach their steady state, constant, values, and we get::

$$
\frac{d_{0}^{\xi}-d_{0}}{d_{0}}=\frac{q^{\xi}-\bar{q}}{1-\beta \xi}
$$

And that leads to the following proposition:

Proposition 8 Consider a deterministic steady state around, $\bar{k}, \bar{d}$ and $\bar{q}$, such that $q^{* h}$ and $q^{* l}$ are close to $\bar{q}=\beta$ and $\bar{q}=\left(q^{* h}+q^{* l}\right) / 2$. Then, a linear approximation around the steady state will satisfy $V\left(\bar{k}, d^{h}, q^{* h}\right)=V\left(\bar{k}, d^{l}, q^{* l}\right)$ when:

$$
\frac{d^{h}-d^{l}}{\bar{d}}=\frac{q^{* h}-q^{* l}}{1-\bar{q}(1-2 \psi)}
$$

where $\bar{d}=\left(d^{h}+d^{l}\right) / 2$.

Proof. See appendix.

Equation 9 is very similar to equation 1, and for small fluctuations of $q^{*}$, they are exactly the same. There are two differences between the case with capital accumulation and the endowment economy. One is that, with capital accumulation, the optimal decision on consumption and savings depends on the state, which influences the value function. But because of the envelope theorem, around the point of maximum, those differences in the choice of $k$ have only second order effects on the value function. It follows that they have no first order impact on the incentive compatible level of debt.

The second difference is that growth prospects have an influence on the incentive compatible level of debt. Proposition 8 shows that in the steady state, debt relief for economies with and without capital coincide. But lemma 7 shows that, outside the steady state, $\Delta d / \bar{d}$ depends not only on the the magnitude of interest rate fluctuations and the persistence of the interest rate process, but also on the current level of capital - and its marginal productivity. The lower is the level of capital, the greater are the marginal 
productivity of capital and the difference between $u^{\prime}(c) \bar{q}$ and $-\beta \frac{\partial V\left(k^{\prime}, d^{\prime}\right)}{\partial d}$, which contribute to increase $\Delta d$ : a switch to the low state that prevents the country from borrowing is more punitive when capital is lower. A lower level of capital also implies lower consumption and, therefore, higher marginal utilities, so present consumption is more important and higher costs of borrowing in the future are less relevant, which induces a decrease in $\Delta d$. Lastly, a higher ratio between future and present debt increases the importance of future costs of borrowing, which induces an increase in $\Delta d$. Thus the overall effect cannot be deduced from the formula. In the numerical examples, $\Delta d$ is slightly decreasing in $k$, implying the effect of the borrowing constraint predominates.

The analysis has focused on the two-state case, but the same insights apply if we consider more general processes. The next proposition considers the case of an autoregressive process for $q^{*}$.

Proposition 9 Suppose that $q^{*}$ follows an $A R(1)$ process:

$$
q_{t+1}^{*}-\bar{q}=\zeta\left(q_{t}^{*}-\bar{q}\right)+\varepsilon_{t+1}
$$

and $\operatorname{Var}\left(\varepsilon_{t}\right)$ is arbitrarily small. If the economy is close to its steady state $\left(k \simeq k^{*}\right)$, $V\left(k, d^{1}, q^{* 1}\right)=V\left(k, d^{2}, q^{* 2}\right)$ for any $\left\{q^{* 1}, q^{* 2}\right\}$ close to $\bar{q}$ and $\left\{d^{1}, d^{2}\right\}$ when:

$$
\frac{d^{1}-d^{2}}{\bar{d}}=\frac{q^{* 1}-q^{* 2}}{1-\beta \zeta}
$$

where $\bar{d}$ is the level of debt in the deterministic model when $q=\bar{q}$.

Proof. See appendix.

\subsection{Stochastic technology}

In this section, I consider fixing the world interest rates at $r^{*}$ and allowing for fluctuations in $A$. Productivity is $A^{h}$ in the high state and $A^{l}$ in the low state, $A^{h}>A^{l}$. It is assumed $q^{*}=\beta$. If the face value of debt $d^{F} \leq d^{l}$, there is no debt reduction and the value functions are:

$$
\begin{aligned}
V_{\text {pay }}^{h}(k, d) & =\max _{k^{\prime}, d^{F}}\left\{u\left(c^{h}\right)+\beta\left[(1-\psi) V_{\text {pay }}^{h}\left(k^{\prime}, d^{F}\right)+\psi V_{\text {pay }}^{l}\left(k^{\prime}, d^{F}\right)\right]\right\} \\
V_{\text {pay }}^{l}(k, d) & =\max _{k^{\prime}, d^{F}}\left\{u\left(c^{l}\right)+\beta\left[(1-\psi) V_{\text {pay }}^{l}\left(k^{\prime}, d^{F}\right)+\psi V_{\text {pay }}^{h}\left(k^{\prime}, d^{F}\right)\right]\right\}
\end{aligned}
$$

where $c^{i}=A^{i} f(k)+(1-\delta) k-k^{\prime}-d+q^{*} d^{F}$ for $i \in\{l, h\}$. If $d^{F} \in\left(d^{l}, d^{h}\right]$, then $d^{l}$ is repayed if $s^{\prime}=l$ and $d^{F}$ is repayed if $s^{\prime}=h$. The value functions associated with 
repayment are:

$$
\begin{aligned}
V_{\text {pay }}^{h}(k, d) & =\max _{k^{\prime}, d^{F}}\left\{u\left(c^{h}\right)+\beta\left[(1-\psi) V_{\text {pay }}^{h}\left(k^{\prime}, d^{F}\right)+\psi V_{\text {pay }}^{l}\left(k^{\prime}, d^{l}\right)\right]\right\} \\
V_{\text {pay }}^{l}(k, d) & =\max _{k^{\prime}, d^{F}}\left\{u\left(c^{l}\right)+\beta\left[(1-\psi) V_{\text {pay }}^{l}\left(k^{\prime}, d^{l}\right)+\psi V_{\text {pay }}^{h}\left(k^{\prime}, d^{F}\right)\right]\right\}
\end{aligned}
$$

where $c^{h}=A^{h} f(k)+(1-\delta) k-k^{\prime}-d+q^{*}\left[(1-\psi) d^{F}+\psi d^{l}\right]$ and $c^{l}=A^{l} f(k)+(1-$ $\delta) k-k^{\prime}-d+q^{*}\left[(1-\psi) d^{l}+\psi d^{F}\right]$.

In case of default, the value functions are:

$$
\begin{aligned}
V_{d e f}^{h}(k, \gamma) & =\max _{k^{\prime}}\left\{u\left((1-\gamma) A^{h} f(k)+(1-\delta) k-k^{\prime}\right)+\beta\left[(1-\psi) V_{d e f}^{h}\left(k^{\prime}, \gamma\right)+\psi V_{d e f}^{l}\left(k^{\prime}, \gamma\right)\right]\right\} \\
V_{d e f}^{l}(k, \gamma) & =\max _{k^{\prime}}\left\{u\left((1-\gamma) A^{l} f(k)+(1-\delta) k-k^{\prime}\right)+\beta\left[(1-\psi) V_{d e f}^{l}\left(k^{\prime}, \gamma\right)+\psi V_{d e f}^{h}\left(k^{\prime}, \gamma\right)\right]\right\}
\end{aligned}
$$

As before, if the marginal productivity of capital is higher than the interest rates $\left(m p k>r^{*}\right)$ and fluctuations $\left(A^{h}-A^{l}\right)$ are small, the country borrows up to a debt limit in each possible future state that ensures it remains incentive compatible for it to repay. The proof is analogous to the proof of Proposition 5. The face value of debt $d^{F}$ is equal to $d^{h}$, and $V_{p a y}^{h}\left(k^{\prime}, d^{h}\right)=V_{d e f}^{h}\left(k^{\prime}, \gamma\right)$ and $V_{\text {pay }}^{l}\left(k^{\prime}, d^{l}\right)=V_{d e f}^{l}\left(k^{\prime}, \gamma\right)$.

As before, we need to obtain an expression for $\Delta d$. The analogy to Proposition 8 for the case of stochastic technology requires the additional assumption that $\gamma$ is arbitrarily small and yields the following result:

Proposition 10 Consider a deterministic steady state, $\{\bar{k}, \bar{d}, \bar{A}\}$, such that $A^{h}$ and $A^{l}$ are close to $\bar{A}=\left(A^{h}+A^{l}\right) / 2$. Then, for arbitrarily small $\gamma$, a linear approximation around the steady state will satisfy $V_{\text {pay }}^{h}\left(k^{\prime}, d^{h}\right)=V_{d e f}^{h}\left(k^{\prime}, \gamma\right)$ and $V_{\text {pay }}^{l}\left(k^{\prime}, d^{l}\right)=V_{\text {def }}^{l}\left(k^{\prime}, \gamma\right)$ when:

$$
\frac{d^{h}-d^{l}}{\bar{d}}=\frac{\left(1-q^{*}\right)}{1-q^{*}(1-2 \psi)} \frac{A^{h}-A^{l}}{\bar{A}}
$$

where $\bar{d}=\left(d^{h}+d^{l}\right) / 2$.

Proof. See appendix.

Equation 10 is exactly the same as equation 2.

\section{The Latin American debt crisis of the 1980's}

In this section, I contrast the predictions of the model with data from the Latin American debt crisis of the 1980's. The results show that the interest rate shock at the beginning of the 1980's can account for a large part of the observed debt relief. 


\subsection{Observed debt relief}

External shocks were important factors in the Latin American debt crisis of the 1980's. As noted by Diaz-Alejandro (1984), countries with different policies and distinct economies ended up in similar crises in the beginning of the 1980's, facing problems that in 1979 would have been considered unlikely.

One key external shock was the increase in US real interest rates, shown in Figure 1 (from Dotsey et al, 2003). In contrast to the 1970's when real interest rates were around 0\%, in the 1980's they were around 4\%. Such large increase in US real interest rates makes the The Latin American crisis a convenient case to evaluate the model's predictions. ${ }^{21}$

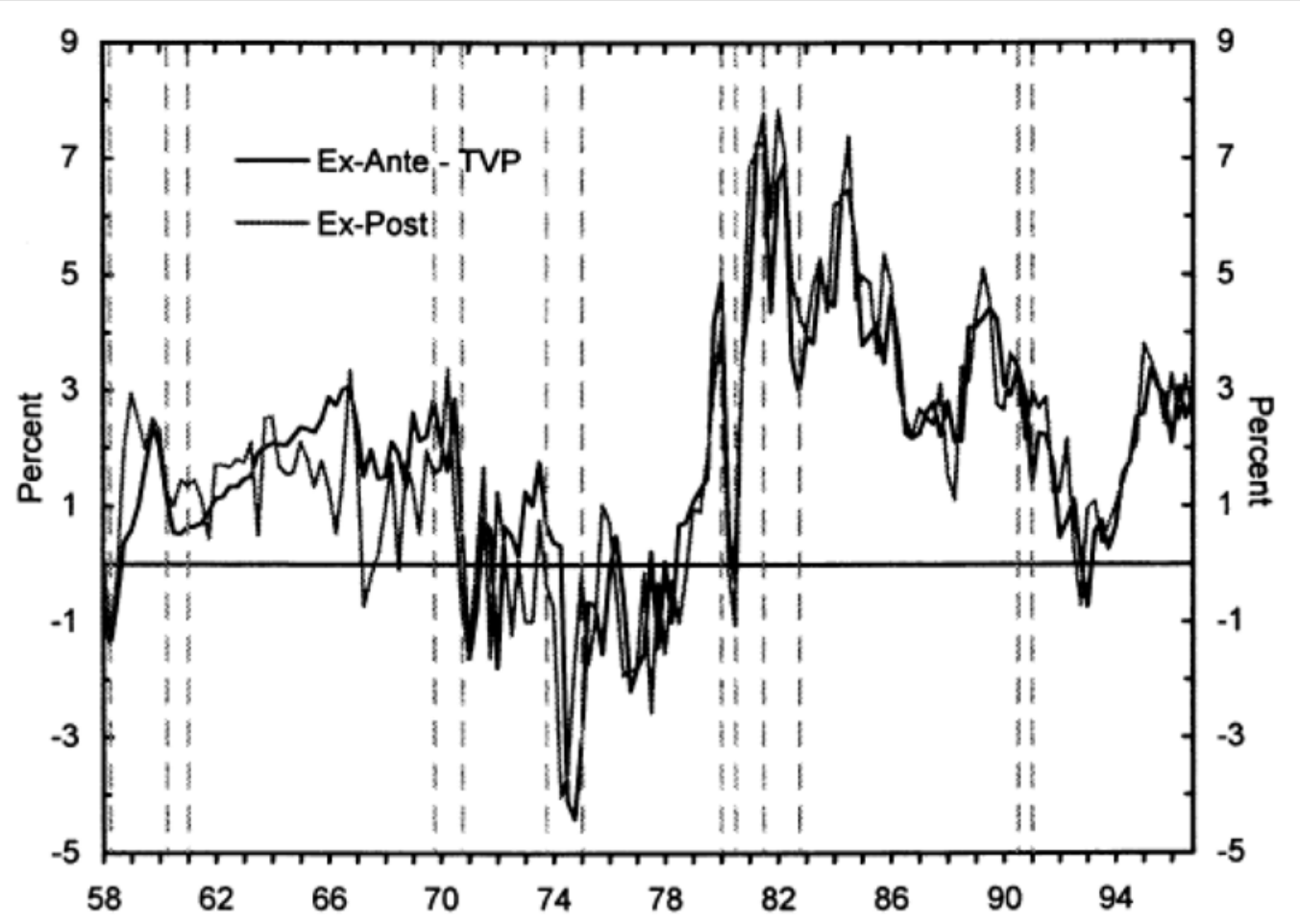

Figure 1: US real interest rates

In the beginning of the 1980's, the prices of Latin American bonds in secondary markets collapsed, capital flows to those economies dried or reverted and the fast process of economic growth of the 1970's stopped. After countless IMF missions, several debt reschedules and some attempts of debt renegotiation (including the Baker Plan), came the Brady agreements, starting in 1989. In the period between 1989 and 1994, most of

\footnotetext{
${ }^{21}$ There are other cases in which interest rate increases in the US contributed to crises in other countries. For example, the sharp increase in US interest rates in 1994 is sometimes mentioned as one of the factors that almost led Mexico to default in December 1994 (see Calvo, Leiderman and Reinhart, 1996).
} 
the main Latin American countries got some debt relief. Table 1 shows the debt relief following the Brady Plan agreements as a percentage of the outstanding long term debt in the main Latin American countries. With the exception of Venezuela, at 20\%, the other four countries are around $30 \%{ }^{22}$

Table 1: Debt relief - Brady plan agreements, Cline (1995)

\begin{tabular}{||cc||}
\hline \hline Venezuela & $20 \%$ \\
\hline Brazil & $28 \%$ \\
\hline Argentina & $29 \%$ \\
\hline Mexico & $30 \%$ \\
\hline Uruguay & $31 \%$ \\
\hline \hline
\end{tabular}

As the Brady agreements did not cover all forms of external debt, the figures in Table 1 should be seen as upper bounds (Cline, 1995).

In the model, renegotiation is costless, instantaneous and the borrower extracts no surplus from the process. In reality, debt relief came ten years after the shock, and what happened in those ten years had some influence on the final agreement. Despite the delay, it is worth comparing the debt relief prescribed by the model and the Brady agreements because the latter were in fact the relief solution to the crisis.

\subsection{Debt relief according to the model}

If the borrowing constraints of the Latin American countries were binding in 1979, then the interest rate rise at the beginning of the 1980's would bring debt, $d$, above its incentive compatible level. In this section, I compute the debt reduction prescribed by the model and compare it to the data.

Consider the model calibrated to represent the 1970's and 1980's. Suppose that world interest rates may be either $0 \%$ or $4 \%$ a year and that each state lasts for an average of 10 years: $q^{* h}=1.00, q^{* l}=1.04^{-1}, \beta=1.02^{-1}$ and $\psi=0.10$. Equation 9 yields the debt reduction given a switch from the high state to the low:

$$
\frac{\Delta d}{\bar{d}}=\frac{1.00-1.04^{-1}}{1-1.02^{-1}(1-2 \times 0.10)}=0.178
$$

\footnotetext{
${ }^{22}$ As noted by Cline (1995), the initial approach for dealing with the problem of debt overhang was aimed both at reducing debt and providing new loans, but "for practical purposes the Brady Plan has been all forgiveness and no new money" (Cline, 1995, page 236). Indeed, according to the model, if the amount of debt exceeds its incentive compatible level, new money will not be made available.
} 
That implies a spread over treasury of $\psi \Delta d / \bar{d}=1.8 \%$ when the state is high but debt relief of $18 \%$ when the state switches to low and interest rates jump from $0 \%$ to $4 \%$. Data from 1973-80 show a spread over treasury of $1.4 \%$ for Brazil and Argentina and $1.1 \%$ for Mexico (Calvo and Kaminsky, 1991).

$\Delta d / \bar{d}$ is not significantly affected by the length of debt contracts. If we work with a period of 5 years instead of one year, $q^{* h}=1.00, q^{* l}=1.04^{-5}, \beta=1.02^{-5}$ and $\psi=0.50$, we still obtain $\left(d^{h}-d^{l}\right) / \bar{d}=0.178$.

The result holds for any $\gamma>0$ and is robust to other interest rates processes. Using the auto-regressive process and assuming a half-life of 3 years for the interest rate increase, the AR-1 coefficient, $\zeta$, would be 0.79 . A jump in real interest rates from $1 \%$ a year to $6 \%$ a year would then imply even greater debt relief: $\Delta d / \bar{d}=22.5 \%$.

In sum, the decrease in the level of debt predicted by the model in response to an interest rate increase of the magnitude observed in the data exceeds half the debt relief of the Brady agreements. In contrast, a negative productivity shock would not generate results of similar magnitude. A huge $10 \%$ reduction in productivity, assuming an average persistence of 10 years $(\psi=0.10)$ and world interest rates of $2 \%$ a year would imply debt reduction slightly below $1 \%$ according to Equation 10 .

Numerical results, presented in the appendix, show that lower marginal productivity of capital (combined with low adjustment costs for capital) reduces the amount of debt relief prescribed by the model, but confirm they are quantitatively important.

\section{Concluding remarks}

Recent quantitative models of sovereign debt aim at explaining the recent debt crisis in Argentina using output shocks. However, according to the model in this paper, output fluctuations do not have a sizable effect on the incentive compatible level of debt nothing remotely close to the observed debt reduction of $71 \% .^{23}$ On the other hand, fluctuations in world interest rates can have a strong impact on the incentive compatible level of sovereign debt.

Given the costs of renegotiating debt, should countries issue debt contingent on world real interest rates? In the case of the Latin American debt crisis of the 1980's, such contracts could have avoided 10 years of costly bargaining. However, while the real interest rate shock of 1980 can be seen as a policy decision, other movements on world

\footnotetext{
${ }^{23}$ The negative correlation between probability of default and output does not tell us about causality, because a high probability of default has a negative impact on output of emerging economies through its impact on interest rates (Neumeyer and Perri, 2005).
} 
real interest rates might be correlated with variables that affect the incentive compatible level of debt, in the opposite direction. For example, the financial crises of 2008/09 led to lower real interest rates but capital outflows from emerging economies. Indeed, FoleyFisher and Guimaraes (2009) find that policy-induced increases in US rates raise default risk in emerging markets, but the overall correlation between default risk and US real interest rates is actually not positive.

Incentives for defaulting on debt depend not on how much a shock affects the country, but on the differential effects of a shock if the country repays and if the country defaults. Output shocks affect a country regardless of its decisions on default. In contrast, world interest rate shocks affect the country only if it keeps interacting with international financial markets, so have a much stronger effect on the incentive compatible level of debt. Other shocks that have an impact on international financial markets could lead to similar effects - for instance, by affecting investors' risk appetite. Fluctuations that affect the country only if it defaults, such as shocks that influence the costs of defaulting, could also have large effects on the incentive compatible level of debt. ${ }^{24}$

\section{A Proofs}

While proving the propositions of the model with capital accumulation, I often use the following method and I refer to it as a first order Taylor approximation. Consider the following Value function:

$$
V(x, y)=\max _{a, b, c}\left\{u(x, y, a, b, c)+\beta V\left(x^{\prime}(a, b, c), y^{\prime}(a, b, c)\right)\right\}
$$

So the values of $a, b, c$ are chosen, which determine the next period's $x, y$ (denoted as a convention by $\left.x^{\prime}, y^{\prime}\right)$. Take the function that is to be maximised:

$$
f(x, y, a, b, c)=u(x, y, a, b, c)+\beta V\left(x^{\prime}(a, b, c), y^{\prime}(a, b, c)\right)
$$

Denote by $a^{*}, b^{*}$ and $c^{*}$ the maximising values of $V(x, y)$ and by $\tilde{a}^{*}, \tilde{b}^{*}$ and $\tilde{c}^{*}$ the maximising values of $V(\tilde{x}, \tilde{y})$. Then $V(x, y)=f\left(x, y, a^{*}, b^{*}, c^{*}\right)$ and $V(\tilde{x}, \tilde{y})=f\left(\tilde{x}, \tilde{y}, \tilde{a}^{*}, \tilde{b}^{*}, \tilde{c}^{*}\right)$. Now, if $(x, y)$ and $(\tilde{x}, \tilde{y})$ are sufficiently close, we can take the approximation of the maximand function with

\footnotetext{
${ }^{24}$ Foley-Fisher (2008) applies the method developed in this paper to study the effect of terms of trade shocks on the incentive compatible level of debt, and contrasts the results to data on debt relief for the highly indepted poor countries. In his model, countries in default are subject to trade sanctions, so shocks to the terms of trade have a large effect on the cost of defaulting. His results show that terms of trade shocks can explain a significant part of the observed debt relief.
} 
respect to the variables to be chosen:

$$
\begin{aligned}
f\left(x, y, a^{*}, b^{*}, c^{*}\right) & \approx f\left(\tilde{x}, \tilde{y}, \tilde{a}^{*}, \tilde{b}^{*}, \tilde{c}^{*}\right)+\sum_{z=x, y, a, b, c} \frac{\partial f\left(\tilde{x}, \tilde{y}, \tilde{a}^{*}, \tilde{b}^{*}, \tilde{c}^{*}\right)}{\partial z}\left(z^{*}-\tilde{z}^{*}\right) \\
& =V(\tilde{x}, \tilde{y})+\sum_{z=x, y, a, b, c}\left(\frac{\partial u\left(\tilde{x}, \tilde{y}, \tilde{a}^{*}, \tilde{b}^{*}, \tilde{c}^{*}\right)}{\partial z}+\beta \frac{\partial V\left(\tilde{x}^{\prime}, \tilde{y}^{\prime}\right)}{\partial z}\right)\left(z^{*}-\tilde{z}^{*}\right)
\end{aligned}
$$

If there is a binding constraint on the possible values of a variable, then its maximised value will be determined by the constraint. Otherwise, the envelope theorem applies and the derivative of $f$ with respect to that variable will be zero.

This method is different from the general first order Taylor approximation: the original function $V(x, y)$ is not a function of the variables with respect to which the approximation is done. This is why the maximand function has to be defined.

\section{A.1 Proposition 1}

Proof. Suppose $q^{F}<q^{l}$. Then the first order condition with respect to $d^{F}$ would have to hold with equality in both states:

$$
\begin{aligned}
& \frac{\partial V^{h}}{\partial d^{F}}=0 \Leftrightarrow\left(q^{* h}-\beta(1-\psi)\right) u^{\prime}\left(c^{h}\right)=\beta \psi u^{\prime}\left(c^{l}\right) \\
& \frac{\partial V^{l}}{\partial d^{F}}=0 \Leftrightarrow\left(q^{* l}-\beta(1-\psi)\right) u^{\prime}\left(c^{l}\right)=\beta \psi u^{\prime}\left(c^{h}\right)
\end{aligned}
$$

$q^{* h}>\beta$ implies $q^{* h}-\beta(1-\psi)>\beta \psi$, so the first first order condition implies $u^{\prime}\left(c^{h}\right)<u^{\prime}\left(c^{l}\right)$. But similarly, $q^{* l}>\beta$ implies $q^{* l}-\beta(1-\psi)>\beta \psi$, so the second first order condition implies $u^{\prime}\left(c^{l}\right)<u^{\prime}\left(c^{h}\right)$. Contradiction.

Now suppose $q^{F} \in\left(q^{l}, q^{h}\right)$. Again, the first order condition with respect to $d^{F}$ would have to hold with equality in both states:

$$
\begin{aligned}
\frac{\partial V^{h}}{\partial d^{F}} & =0 \Leftrightarrow u^{\prime}\left(c^{h}\right) q^{* h}(1-\psi)=\beta(1-\psi) u^{\prime}\left(c^{h}\right) \\
\frac{\partial V^{l}}{\partial d^{F}} & =0 \Leftrightarrow u^{\prime}\left(c^{l}\right) q^{* l} \psi=\beta \psi u^{\prime}\left(c^{h}\right)
\end{aligned}
$$

which contradicts the assumptions that $\beta<q^{* l}$ and $c^{l} \leq c^{h}$.

\section{A.2 Proposition 4}

Proof. The value functions in case of repayment and in case of default are maximised at $\left(k_{p}^{\prime}, d_{p}^{\prime}\right)$ and $\left(k_{d}^{\prime}\right)$ respectively, which means that:

$$
\begin{aligned}
V_{\text {pay }}(k, d) & =u\left(y+(1-\delta) k-k_{p}^{\prime}-d+q d_{p}^{\prime}\right)+\beta V_{\text {pay }}\left(k_{p}^{\prime}, d_{p}^{\prime}\right) \\
V_{\text {def }}(k, \gamma) & =u\left(y+(1-\delta) k-k_{d}^{\prime}-\gamma y\right)+\beta V_{\text {def }}\left(k_{d}^{\prime}, \gamma\right)
\end{aligned}
$$


When $d=d^{\prime}=0$ and $\gamma=0$, the value functions are identical in the two cases, $V_{0}(k)$. It is maximised by choosing $k^{\prime}=k_{o}^{\prime}$.

Consider $(k, d, \gamma)$ such that the country is indifferent between repaying and choosing $\left(k_{p}^{\prime}, d^{\prime}\right)$ or defaulting and choosing $\left(k_{d}^{\prime}\right)$, which means that $V_{\text {pay }}(k, d)=V_{\text {def }}(k, \gamma)$. Approximate the functions that are to be maximised,

$$
\begin{aligned}
f_{\text {pay }}\left(d, k^{\prime}, d^{\prime}\right) & =u\left(y+(1-\delta) k-k^{\prime}-d+q d^{\prime}\right)+\beta V_{\text {pay }}\left(k^{\prime}, d^{\prime}\right) \\
f_{\text {def }}\left(k^{\prime}, \gamma\right) & =u\left(y+(1-\delta) k-k^{\prime}-\gamma y\right)+\beta V_{\text {def }}\left(k^{\prime}, \gamma\right)
\end{aligned}
$$

around $V_{0}(k)$. The first order Taylor approximation of these functions around $V_{0}(k)$ with respect to $\left(k^{\prime}, d, d^{\prime}\right)$ or $\left(k^{\prime}, \gamma\right)$ respectively yields

$$
\begin{aligned}
f_{\text {pay }}\left(d, k^{\prime}, d^{\prime}\right)= & V_{\text {pay }}(k, 0)+\frac{\partial f_{\text {pay }}\left(0, k_{o}^{\prime}, 0\right)}{\partial d}(d-0)+\frac{\partial f_{\text {pay }}\left(0, k_{o}^{\prime}, 0\right)}{\partial d^{\prime}}\left(d^{\prime}-0\right) \\
& +\frac{\partial f_{\text {pay }}\left(0, k_{o}^{\prime}, 0\right)}{\partial k^{\prime}}\left(k^{\prime}-k_{o}^{\prime}\right)+O_{k, p} \\
= & V_{0}(k)+u^{\prime}\left(c_{o}\right)\left(-d+q d^{\prime}\right)+\beta \frac{\partial V_{\text {pay }}\left(k_{o}^{\prime}, 0\right)}{\partial d^{\prime}} d^{\prime}+O_{k, p} \\
f_{\text {def }}\left(k^{\prime}, \gamma\right)= & V_{\text {def }}(k, 0)+\frac{\partial f_{\text {def }}\left(k_{o}^{\prime}, 0\right)}{\partial \gamma}(\gamma-0)+\frac{\partial f_{\text {def }}\left(k_{o}^{\prime}, 0\right)}{\partial k^{\prime}}\left(k^{\prime}-k_{o}^{\prime}\right)+O_{k, d} \\
= & V_{0}(k)-u^{\prime}\left(c_{o}\right) \gamma y+\beta \frac{\partial V_{d e f}\left(k_{o}^{\prime}, 0\right)}{\partial \gamma} \gamma+O_{k, d}
\end{aligned}
$$

Where I used that since $\frac{\partial V_{\text {pay }}}{\partial k^{\prime}}=\frac{\partial V_{d e f}}{\partial k^{\prime}}=0$ due to the Envelope condition for the unconstrained maximization of $V_{\text {pay }}$ and $V_{d e f}$ with respect to $k^{\prime}$, their evaluation $\frac{\partial V_{\text {pay }}(k, 0)}{\partial k^{\prime}}=$ $\frac{\partial V_{d e f}(k, 0)}{\partial k^{\prime}}=0$ as well. The optimal consumption with no borrowing, no punishment is denoted by $c_{o}=y+(1-\delta) k-k_{o}^{\prime}$. Furthermore, $\lim _{\left(d, d^{\prime}, k^{\prime}\right) \rightarrow\left(0,0, k_{o}^{\prime}\right)} \frac{O_{k, p}}{\left\|d, d^{\prime}, k^{\prime}\right\|^{2}}=0$ and $\lim _{\left(\gamma, k^{\prime}\right) \rightarrow\left(0, k_{o}^{\prime}\right)} \frac{O_{k, p}}{\left\|\gamma, k^{\prime}\right\|^{2}}=0$.

Note that $V_{\text {pay }}(k, d)=V_{\text {def }}(k, \gamma) \Longleftrightarrow f_{\text {pay }}\left(d, k_{p}^{\prime}, d^{\prime}\right)=f_{\text {def }}\left(k_{d}^{\prime}, \gamma\right)$. Using the first order Taylor expansions at points $\left(d, k_{p}^{\prime}, d^{\prime}\right)$ and $\left(k_{d}^{\prime}, \gamma\right)$, we get:

$$
u^{\prime}\left(c_{o}\right)\left(-d+q d^{\prime}+\gamma y\right)+\beta\left(\frac{\partial V_{p a y}\left(k_{o}^{\prime}, 0\right)}{\partial d^{\prime}} d^{\prime}-\frac{\partial V_{d e f}\left(k_{o}^{\prime}, 0\right)}{\partial \gamma} \gamma\right)+\left(O_{k, p}-O_{k, d}\right)=0 .
$$

The last part is to show that $\frac{\partial V_{\text {pay }}\left(k_{o}^{\prime}, 0\right)}{\partial d^{\prime}} d^{\prime}-\frac{\partial V_{d e f}\left(k_{o}^{\prime}, 0\right)}{\partial \gamma} \gamma$ is approximately zero.

If $k<k^{*}$ then the country borrows the maximum level of incentive compatible debt. This debt level makes the country indifferent between repaying and defaulting at $\left(k_{p}^{\prime}, d^{\prime}\right)$ :

$$
V_{\text {pay }}\left(k_{p}^{\prime}, d^{\prime}\right)=V_{\text {def }}\left(k_{p}^{\prime}, \gamma\right)
$$

First order Taylor approximations of $V_{\text {pay }}\left(k_{p}^{\prime}, d^{\prime}\right)$ and $V_{\text {def }}\left(k_{p}^{\prime}, \gamma\right)$ around $V_{o}\left(k_{o}^{\prime}\right)$ with respect 
to only $k^{\prime}, d^{\prime}$ and $\gamma$ yield:

$$
\begin{aligned}
& V_{\text {pay }}\left(k_{p}^{\prime}, d^{\prime}\right)=V_{0}\left(k_{p}^{\prime}\right)+\frac{\partial V_{\text {pay }}\left(k_{o}^{\prime}, 0\right)}{\partial k^{\prime}} \cdot\left(k_{p}^{\prime}-k_{o}^{\prime}\right)+\frac{\partial V_{\text {pay }}\left(k_{o}^{\prime}, 0\right)}{\partial d^{\prime}} \cdot d^{\prime}+O_{k^{\prime}}\left(d^{\prime 2}\right) \\
& V_{d e f}\left(k_{p}^{\prime}, \gamma\right)=V_{0}\left(k_{p}^{\prime}\right)+\frac{\partial V_{d e f}\left(k_{o}^{\prime}, 0\right)}{\partial k^{\prime}} \cdot\left(k_{p}^{\prime}-k_{o}^{\prime}\right)+\frac{\partial V_{d e f}\left(k_{o}^{\prime}, 0\right)}{\partial \gamma} \cdot \gamma+O_{k^{\prime}}\left(\gamma^{2}\right)
\end{aligned}
$$

$V_{\text {pay }}\left(k_{p}^{\prime}, d^{\prime}\right)=V_{\text {def }}\left(k_{p}^{\prime}, \gamma\right)$ implies:

$$
\frac{\partial V_{\text {pay }}\left(k_{p}^{\prime}, 0\right)}{\partial d^{\prime}} \cdot d^{\prime}-\frac{\partial V_{d e f}\left(k_{p}^{\prime}, 0\right)}{\partial \gamma} \cdot \gamma \approx 0
$$

Using this last equation the difference of the original Taylor expansions simplifies to:

$$
u^{\prime}\left(c_{o}\right)\left(-d+q d^{\prime}+\gamma y\right)+\left(O_{k, p}-O_{k, d}\right) \approx 0
$$

$u^{\prime}\left(c_{o}\right) \neq 0$, and $\left(O_{k, p}-O_{k, d}\right)$ is very small near $\left(d, d^{\prime}, k^{\prime}\right)=\left(0,0, k_{p}^{\prime}\right)$ and $\left(\gamma, k^{\prime}\right)=\left(0, k_{d}^{\prime}\right)$ imply that

$$
-d+q d^{\prime}+\gamma y=0 \Longleftrightarrow d=q d^{\prime}+\gamma y
$$

Which yields the second part of the claim. In steady state, $d=d^{\prime}$, and we get the first part of the claim.

\section{A.3 Proposition 5}

Proof. First, consider $s=h$ and $d^{F}$ is such that $d^{l}<d^{F}<d^{h}$. The first order condition with respect to $d^{F}$ would have to hold with equality. The first order conditions with respect to $k^{\prime}$ and $d^{F}$ are:

$$
\begin{aligned}
u^{\prime}\left(c_{t}^{h}\right) & =\left(A f^{\prime}\left(k^{\prime}\right)+1-\delta\right) \beta\left[(1-\psi) u^{\prime}\left(c_{t+1}^{h}\right)+\psi u^{\prime}\left(c_{t+1}^{l}\right)\right] \\
u^{\prime}\left(c_{t}^{h}\right) q^{* h}(1-\psi) & =\beta(1-\psi) u^{\prime}\left(c_{t+1}^{h}\right)
\end{aligned}
$$

Combining both yields:

$$
1=q^{* h}\left(A f^{\prime}\left(k^{\prime}\right)+1-\delta\right)\left(1-\psi\left[1-\frac{u^{\prime}\left(c_{t+1}^{l}\right)}{u^{\prime}\left(c_{t+1}^{h}\right)}\right]\right)
$$

As $c_{t+1}^{l}$ and $c_{t+1}^{h}$ are similar, that implies:

$$
\frac{1}{q^{* h}}-1 \approx A f^{\prime}\left(k^{\prime}\right)-\delta
$$

which contradicts the assumption that $m p k>r^{* h}$.

If $s=l$ and $d^{F}$ is such that $d^{l}<d^{F}<d^{h}$, a similar procedure leads to

$$
1=q^{* l}\left(A f^{\prime}\left(k^{\prime}\right)+1-\delta\right)\left(1-(1-\psi)\left[1-\frac{u^{\prime}\left(c_{t+1}^{l}\right)}{u^{\prime}\left(c_{t+1}^{h}\right)}\right]\right)
$$


which also contradicts the assumption that $m p k>r^{* h}$.

Last, if $d^{F}<d^{l}$, combining the first order conditions with respect to $d^{F}$ and $k^{\prime}$ yields:

$$
\frac{1}{q^{* i}}-1=A f^{\prime}\left(k^{\prime}\right)-\delta
$$

for $i \in\{l, h\}$, which is a contradiction.

\section{A.4 Lemma 6}

Before proving lemma 6, we need an auxiliary result:

Lemma 11 Consider the model with 2 states, $h$ and $l$, and probability of changing state equal to $\psi$. Define $\bar{q}=\left(q^{h}+q^{l}\right) / 2$. In a first order approximation,

$$
V(k, d, \bar{q})=\left[V\left(k, d, q^{h}\right)+V\left(k, d, q^{l}\right)\right] \div 2
$$

Proof. Proof: Comes directly from a Taylor expansion of $V\left(\bar{k}, \bar{d}, q^{h}\right)$ and $V\left(\bar{k}, \bar{d}, q^{l}\right)$ around $V(\bar{k}, \bar{d}, \bar{q})$.

We are ready to prove lemma 6 .

Proof. First, we need to show that, close to the deterministic steady state $(k=\bar{k}, d=\bar{d})$, $V\left(\bar{k}, \bar{d}, q^{h}\right)=V^{\xi}\left(\bar{k}, \bar{d}, q^{h}\right)$ if $\xi=1-2 \psi$.

$$
V^{\xi}\left(k, d, q^{h}\right)=\max _{k^{\prime}, d^{\prime}, \Delta d}\left\{\begin{array}{c}
u\left(A f(k)+(1-\delta) k-k^{\prime}-d+q^{h} d^{\prime}\right) \\
+\beta\left[(1-\xi) V^{\operatorname{det}}\left(k^{\prime}, d^{\prime}-\xi \Delta d\right)+\xi V^{\xi}\left(k^{\prime}, d^{\prime}+(1-\xi) \Delta d, q^{h}\right)\right]
\end{array}\right\}
$$

Near the deterministic steady state, choosing the optimal $\left(d^{\prime}, k^{\prime}\right)$ instead of $(\bar{d}, \bar{k})$ has only second order effect on the value function $V^{\xi}$. As a first order approximation, we can write:

$$
\begin{aligned}
V^{\xi}\left(\bar{k}, \bar{d}, q^{h}\right) & =u\left(c^{h}\right)+\beta\left[(1-\xi) V^{\operatorname{det}}(\bar{k}, \bar{d}-\xi \Delta d)+\xi V^{\xi}\left(\bar{k}, \bar{d}+(1-\xi) \Delta d, q^{h}\right)\right] \\
V^{\operatorname{det}}(\bar{k}, \bar{d}) & =u(\bar{c})+\beta V^{\operatorname{det}}(\bar{k}, \bar{d})
\end{aligned}
$$

where $c_{h}=A f(\bar{k})-\delta \bar{k}-\bar{d}\left(1-q^{h}\right)$ and $\bar{c}=A f(\bar{k})-\delta \bar{k}-\bar{d}(1-\bar{q})$.

Taking a first order Taylor approximation of $f^{\xi}\left(\bar{k}, \bar{d}, q^{h}, \Delta d\right)=V^{\xi}\left(\bar{k}, \bar{d}, q^{h}\right)$ around $V^{\operatorname{det}}(\bar{k}, \bar{d})$ $\left(q^{h}=\bar{q}\right.$ and $\left.\Delta d=0\right)$ with respect to $q, \Delta d$, we get:

$$
\begin{aligned}
V^{\xi}\left(\bar{k}, \bar{d}, q^{h}\right) \approx & u(\bar{c})+u^{\prime}(\bar{c})\left(q^{h}-\bar{q}\right) \bar{d}+\beta\left(V^{\operatorname{det}}(\bar{k}, \bar{d})+(1-\xi) \frac{\partial V^{\operatorname{det}}(\bar{k}, \bar{d})}{\partial d}(-\xi)(\Delta d-0)\right) \\
& +\beta \xi\left(\frac{\partial V^{\xi}(\bar{k}, \bar{d}, \bar{q})}{\partial d}(1-\xi)(\Delta d-0)+\frac{\partial V^{\xi}(\bar{k}, \bar{d}, \bar{q})}{\partial q}\left(q^{h}-\bar{q}\right)\right) \\
= & u(\bar{c})+u^{\prime}(\bar{c})\left(q^{h}-\bar{q}\right) \bar{d}+\beta V^{\operatorname{det}}(\bar{k}, \bar{d})+\beta\left(q^{h}-\bar{q}\right) \xi \frac{\partial V^{\xi}(\bar{k}, \bar{d}, \bar{q})}{\partial q}
\end{aligned}
$$

As a simple first order Taylor approximation, $\frac{\partial V^{\xi}(\bar{k}, \bar{d}, \bar{q})}{\partial q}\left(q^{h}-\bar{q}\right)=V^{\xi}\left(\bar{k}, \bar{d}, q^{h}\right)-V^{\xi}(\bar{k}, \bar{d}, \bar{q})$, so the above approximation can be written as:

$$
V^{\xi}\left(\bar{k}, \bar{d}, q^{h}\right)=u(\bar{c})+u^{\prime}(\bar{c})\left(q^{h}-\bar{q}\right) \bar{d}+\beta V^{\operatorname{det}}(\bar{k}, \bar{d})+\beta \xi\left[V^{\xi}\left(\bar{k}, \bar{d}, q^{h}\right)-V^{\xi}(\bar{k}, \bar{d}, \bar{q})\right]
$$


Since $V^{\xi}(\bar{k}, \bar{d}, \bar{q})=V^{\operatorname{det}}(\bar{k}, \bar{d})=u(\bar{c})+\beta V^{\operatorname{det}}(\bar{k}, \bar{d})$,

$$
V^{\xi}\left(\bar{k}, \bar{d}, q^{h}\right)-V^{\operatorname{det}}(\bar{k}, \bar{d})=u^{\prime}(\bar{c})\left(q^{h}-\bar{q}\right) \bar{d}+\beta \xi\left[V^{\xi}\left(\bar{k}, \bar{d}, q^{h}\right)-V^{\operatorname{det}}(\bar{k}, \bar{d})\right]
$$

so

$$
V^{\xi}\left(\bar{k}, \bar{d}, q^{h}\right)-V^{\operatorname{det}}(\bar{k}, \bar{d})=\frac{u^{\prime}(\bar{c})\left(q^{h}-\bar{q}\right) \bar{d}}{1-\beta \xi}
$$

Now, note that, as a first order approximation:

$$
\begin{aligned}
V\left(\bar{k}, \bar{d}, q^{h}\right)-V^{\operatorname{det}}(\bar{k}, \bar{d}) & =u^{\prime}(\bar{c})\left(q^{h}-\bar{q}\right) \bar{d}+\beta\left[(1-\psi) V\left(\bar{k}, \bar{d}, q^{h}\right)+\psi V\left(\bar{k}, \bar{d}, q^{l}\right)-V^{\operatorname{det}}(\bar{k}, \bar{d})\right] \\
& =u^{\prime}(\bar{c})\left(q^{h}-\bar{q}\right) \bar{d}+\beta(1-2 \psi)\left[V\left(\bar{k}, \bar{d}, q^{h}\right)-V^{\operatorname{det}}(\bar{k}, \bar{d})\right]
\end{aligned}
$$

the last equality follows from lemma 11. Then:

$$
V\left(\bar{k}, \bar{d}, q^{h}\right)-V^{\operatorname{det}}(\bar{k}, \bar{d})=\frac{u^{\prime}(\bar{c})\left(q^{h}-\bar{q}\right) \bar{d}}{1-\beta(1-2 \psi)}
$$

If $\xi=1-2 \psi$, Equations (11) and (12) imply that $V\left(\bar{k}, \bar{d}, q^{h}\right)=V^{\xi}\left(\bar{k}, \bar{d}, q^{h}\right)$.

Now, we complete the proof by induction. Away from the steady state, we have:

$$
V^{\xi}\left(k, d, q^{h}\right)=u\left(A f(k)+(1-\delta) k-k^{\prime}-d+q^{h} d\right)+\beta\left[\xi V^{\xi}\left(k^{\prime}, d^{\prime}, q^{h}\right)+(1-\xi) V^{\operatorname{det}}\left(k^{\prime}, d^{\prime}\right)\right]
$$

and

$$
V\left(k, d, q^{h}\right)=u\left(A f(k)+(1-\delta) k-k^{\prime}-d+q^{h} d\right)+\beta\left[(1-\psi) V\left(k^{\prime}, d^{\prime}, q^{h}\right)+\psi V^{\operatorname{det}}\left(k^{\prime}, d^{\prime}\right)\right]
$$

If $V^{\xi}\left(k^{\prime}, d^{\prime}, q^{h}\right)=V\left(k^{\prime}, d^{\prime}, q^{h}\right)$, then, using lemma 11, we can write:

$$
V\left(k, d, q^{h}\right)=u\left(A f(k)+(1-\delta) k-k^{\prime}-d+q^{h} d\right)+\beta\left[\xi V^{\xi}\left(k^{\prime}, d^{\prime}, q^{h}\right)+(1-\xi) V^{\operatorname{det}}\left(k^{\prime}, d^{\prime}\right)\right]
$$

and thus $V^{\xi}\left(k, d, q^{h}\right)=V\left(k, d, q^{h}\right)$.

\section{A.5 Lemma 7}

Proof. Subscripts denote time ( $k_{0}$ is capital at time 0 ). The superscript $\xi$ for $t>0$ means that at time $t-1$, when the variable ( $k$ or $d$ ) has been chosen, $q^{*}=q^{* \xi}$.

$$
V^{\xi}\left(k_{0}, d_{0}^{\xi}, q^{\xi}\right)=\max _{k_{1}^{\xi}, d_{1}^{\xi}, \Delta d}\left\{\begin{array}{c}
u\left(A f\left(k_{o}\right)+(1-\delta) k_{o}-k_{1}^{\xi}-d_{0}^{\xi}+q^{* \xi} d_{1}^{\xi}\right) \\
+\beta\left[(1-\xi) V^{\operatorname{det}}\left(k_{1}^{\xi}, d_{1}^{\xi}-\xi \Delta d\right)+\xi V^{\xi}\left(k_{1}^{\xi}, d_{1}^{\xi}+(1-\xi) \Delta d, q^{* \xi}\right)\right]
\end{array}\right\}
$$

again define the function to be maximised:

$$
\begin{aligned}
f\left(k_{0}, d_{0}^{\xi}, q^{\xi}, k_{1}^{\xi}, d_{1}^{\xi}, \Delta d\right)= & u\left(A f\left(k_{o}\right)+(1-\delta) k_{o}-k_{1}^{\xi}-d_{0}^{\xi}+q^{* \xi} d_{1}^{\xi}\right) \\
& +\beta\left[(1-\xi) V^{\operatorname{det}}\left(k_{1}^{\xi}, d_{1}^{\xi}-\xi \Delta d\right)+\xi V^{\xi}\left(k_{1}^{\xi}, d_{1}^{\xi}+(1-\xi) \Delta d, q^{* \xi}\right)\right]
\end{aligned}
$$


and take a Taylor approximation with respect to $k_{1}, d_{0}, d_{1}, q, \Delta d$ around $q=\bar{q}, d=d_{0}, \Delta d=0$ that is when $f()=V^{\operatorname{det}}\left(k_{0}, d_{0}\right)$.

$$
\begin{aligned}
& V^{\xi}\left(k_{0}, d_{0}^{\xi}, q^{* \xi}\right)=f\left(k_{0}, d_{0}^{\xi}, q^{* \xi}, k_{1}^{\xi}, d_{1}^{\xi}, \Delta d\right) \\
\approx & u\left(A f\left(k_{o}\right)+(1-\delta) k_{o}-k_{1}-d_{0}+\bar{q} d_{1}\right)+\beta\left[(1-\xi) V^{\operatorname{det}}\left(k_{1}, d_{1}\right)+\xi V^{\xi}\left(k_{1}, d_{1}, \bar{q}\right)\right] \\
& +\frac{\partial f\left(k_{0}, d_{0}, \bar{q}, k_{1}, d_{1}, 0\right)}{\partial k_{1}}\left(k_{1}^{\xi}-k_{1}\right)+\frac{\partial f\left(k_{0}, d_{0}, \bar{q}, k_{1}, d_{1}, 0\right)}{\partial d_{0}}\left(d_{0}^{\xi}-d_{0}\right) \\
& +\frac{\partial f\left(k_{0}, d_{0}, \bar{q}, k_{1}, d_{1}, 0\right)}{\partial d_{1}}\left(d_{1}^{\xi}-d_{1}\right)+\frac{\partial f\left(k_{0}, d_{0}, \bar{q}, k_{1}, d_{1}, 0\right)}{\partial q}\left(q^{* \xi}-\bar{q}\right) \\
& +\frac{\partial f\left(k_{0}, d_{0}, \bar{q}, k_{1}, d_{1}, 0\right)}{\partial \Delta d}(\Delta d-0) \\
= & V^{\operatorname{det}}\left(k_{0}, d_{0}\right)+\beta \xi\left[V^{\xi}\left(k_{1}, d_{1}, \bar{q}\right)-V^{\operatorname{det}}\left(k_{1}, d_{1}\right)\right]+u^{\prime}\left(c_{0}\right)\left[-\left(d_{0}^{\xi}-d_{0}\right)+\bar{q}\left(d_{1}^{\xi}-d_{1}\right)+d_{1}\left(q^{* \xi}-\bar{q}\right)\right] \\
& +\beta \frac{\partial V^{\operatorname{det}}\left(k_{1}, d_{1}\right)}{\partial d_{1}}\left\{(1-\xi)\left[\left(d_{1}^{\xi}-d_{1}\right)-\xi(\Delta d-0)\right]\right\} \\
& +\beta \frac{\partial V^{\xi}\left(k_{1}, d_{1}, \bar{q}\right)}{\partial d_{1}}\left\{\xi\left[\left(d_{1}^{\xi}-d_{1}\right)+(1-\xi)(\Delta d-0)\right]\right\}+\beta \xi \frac{\partial V^{\xi}\left(k_{1}, d_{1}, \bar{q}\right)}{\partial q}\left(q^{* \xi}-\bar{q}\right)
\end{aligned}
$$

Where I used that $V^{\operatorname{det}}\left(k_{0}, d_{0}\right)=u\left(A f\left(k_{o}\right)+(1-\delta) k_{o}-k_{1}-d_{0}+\bar{q} d_{1}\right)+\beta V^{\operatorname{det}}\left(k_{1}, d_{1}\right)$.

Note that as a first order Taylor approximation:

$$
\begin{aligned}
V^{\xi}\left(k_{1}, d_{1}, q^{* \xi}\right) & =V^{\xi}\left(k_{1}, d_{1}, \bar{q}\right)+\beta\left[(1-\xi) \frac{\partial V^{\operatorname{det}}\left(k_{1}, d_{1}\right)}{\partial q}+\xi \frac{\partial V^{\xi}\left(k_{1}, d_{1}, \bar{q}\right)}{\partial q}\right]\left(q^{* \xi}-\bar{q}\right) \\
& =V^{\xi}\left(k_{1}, d_{1}, \bar{q}\right)+\beta \xi \frac{\partial V^{\xi}\left(k_{1}, d_{1}, \bar{q}\right)}{\partial q}\left(q^{* \xi}-\bar{q}\right)
\end{aligned}
$$

Vhen $q=\bar{q}, V^{\operatorname{det}}\left(k_{1}, d_{1}\right)=V^{\xi}\left(k_{1}, d_{1}, \bar{q}\right)$ and $\frac{\partial V^{\operatorname{det}}\left(k_{1}, d_{1}\right)}{\partial d_{1}}=\frac{\partial V^{\xi}\left(k_{1}, d_{1}, \bar{q}\right)}{\partial d_{1}}$. Using these last equations I get:

$$
\begin{aligned}
V^{\xi}\left(k_{0}, d_{0}^{\xi}, q^{* \xi}\right)-V^{\operatorname{det}}\left(k_{0}, d_{0}\right)= & u^{\prime}\left(c_{0}\right)\left[-\left(d_{0}^{\xi}-d_{0}\right)+\bar{q}\left(d_{1}^{\xi}-d_{1}\right)+d_{1}\left(q^{* \xi}-\bar{q}\right)\right] \\
& +\beta \frac{\partial V^{\xi}\left(k_{1}, d_{1}, \bar{q}\right)}{\partial d_{1}}\left(d_{1}^{\xi}-d_{1}\right)+\beta \xi\left[V^{\xi}\left(k_{1}, d_{1}, q^{* \xi}\right)-V^{\operatorname{det}}\left(k_{1}, d_{1}\right)\right] .
\end{aligned}
$$

Analogously, for $t>0$ and starting with equal initial debts at both states, we get:

$$
\begin{aligned}
V^{\xi}\left(k_{t}, d_{t}, q^{* \xi}\right)-V^{\operatorname{det}}\left(k_{t}, d_{t}\right)= & u^{\prime}\left(c_{t}\right)\left[\bar{q}\left(d_{t+1}^{\xi}-d_{t+1}\right)+d_{t+1}\left(q^{* \xi}-\bar{q}\right)\right] \\
& +\beta \frac{\partial V^{\xi}\left(k_{t+1}, d_{t+1}, \bar{q}\right)}{\partial d_{t+1}}\left(d_{t+1}^{\xi}-d_{t+1}\right) \\
& +\beta \xi\left[V^{\xi}\left(k_{t+1}, d_{t+1}, q^{* \xi}\right)-V^{\operatorname{det}}\left(k_{t+1}, d_{t+1}\right)\right]
\end{aligned}
$$

Recursive substitution leads to

$$
\begin{aligned}
& V^{\xi}\left(k_{0}, d_{0}^{\xi}, q^{* \xi}\right)-V^{\operatorname{det}}\left(k_{0}, d_{0}\right)=-u^{\prime}\left(c_{0}\right)\left(d_{0}^{\xi}-d_{0}\right) \\
& +\sum_{t=0}^{\infty}(\beta \xi)^{t}\left[u^{\prime}\left(c_{t}\right)\left[\bar{q}\left(d_{t+1}^{\xi}-d_{t+1}\right)+d_{t+1}\left(q^{* \xi}-\bar{q}\right)\right]+\beta \frac{\partial V^{\operatorname{det}}\left(k_{t+1}, d_{t+1}\right)}{\partial d_{t+1}}\left(d_{t+1}^{\xi}-d_{t+1}\right)\right]
\end{aligned}
$$

Imposing $V^{\xi}\left(k_{0}, d_{0}^{\xi}, q^{* \xi}\right)=V^{\operatorname{det}}\left(k_{0}, d_{0}\right)$ we get the claim. 


\section{A.6 Proposition 8}

Proof. Using Lemma 6 and Equation 8:

$$
\begin{aligned}
V\left(\bar{k}, d^{h}, q^{* h}\right) & =V(\bar{k}, \bar{d}, \bar{q}) \Rightarrow \\
V^{\xi}\left(\bar{k}, d^{h}, q^{* h}\right) & =V(\bar{k}, \bar{d}, \bar{q}) \Rightarrow \\
\frac{d^{h}-\bar{d}}{\bar{d}} & =\frac{q^{* h}-\bar{q}}{1-\beta(1-2 \psi)}
\end{aligned}
$$

Analogously, $V\left(\bar{k}, d^{l}, q^{* l}\right)=V(\bar{k}, \bar{d}, \bar{q}) \Rightarrow$

$$
\frac{d^{l}-\bar{d}}{\bar{d}}=\frac{q^{* l}-\bar{q}}{1-\beta(1-2 \psi)}
$$

Using both equations, we get the claim.

\section{A.7 Proposition 9}

Proof. Consider a Taylor approximation of $V^{A R}\left(\bar{k}, d^{i}, q^{* i}\right)$ around the deterministic steady state $\left(V^{\operatorname{det}}(\bar{k}, \bar{d}, \bar{q})\right)$. The borrowing constraint is not binding, so choosing the optimal $\left(d^{\prime}, k^{\prime}\right)$ instead of $(\bar{k}, \bar{d})$ has only second order effects on the value function $V^{A R}$. As a first order approximation, we can write:

$$
\begin{aligned}
V^{A R}\left(\bar{k}, d^{i}, q^{* i}\right) & =E\left(\sum_{t=0}^{\infty} \beta^{t} u\left(A f\left(k_{t}\right)+(1-\delta) k_{t}-k_{t+1}-d_{t}^{i}+q^{* i} d_{t+1}^{i}\right)\right) \\
& \approx \sum_{t=0}^{\infty} \beta^{t} u(\bar{c})+E\left(\sum_{t=0}^{\infty} \beta^{t} u^{\prime}(\bar{c}) \bar{d}\left(q_{t}^{* i}-\bar{q}\right)\right)-u^{\prime}(\bar{c})\left(d_{0}^{i}-\bar{d}\right)
\end{aligned}
$$

Where $\bar{c}=A f(\bar{k})-\delta \bar{k}-(1-\bar{q}) \bar{d}$.

Looking at the middle part of this expression,

$$
\begin{aligned}
& E\left(\sum_{t=0}^{\infty} \beta^{t} u^{\prime}(\bar{c}) \bar{d}\left(q_{t}^{* i}-\bar{q}\right)\right) \\
= & u^{\prime}(\bar{c}) \bar{d}\left[\left(q_{0}^{* i}-\bar{q}\right)+E\left(\beta\left(\zeta\left(q_{0}^{* i}-\bar{q}\right)+\varepsilon_{1}\right)+\beta^{2}\left(\zeta\left(\zeta\left(q_{0}^{* i}-\bar{q}\right)+\varepsilon_{1}\right)+\varepsilon_{2}\right)+\ldots\right)\right] \\
= & u^{\prime}(\bar{c}) \bar{d}\left[\left(q_{0}^{* i}-\bar{q}\right) \sum_{t=0}^{\infty}(\beta \zeta)^{t}+E\left(\sum_{t=1}^{\infty} \beta^{t} \varepsilon_{t} \frac{1}{1-\beta \zeta}\right)\right] \\
= & \sum_{t=0}^{\infty}(\beta \zeta)^{t} u^{\prime}(\bar{c}) \bar{d}\left(q_{0}^{* i}-\bar{q}\right)=u^{\prime}(\bar{c}) \bar{d}\left(q_{0}^{* i}-\bar{q}\right) \frac{1}{1-\beta \zeta}
\end{aligned}
$$

So:

$$
V^{A R}\left(k, d^{i}, q^{* i}\right) \approx \sum_{t=0}^{\infty} \beta^{t} u(\bar{c})+u^{\prime}(\bar{c}) \bar{d}\left(q_{0}^{* i}-\bar{q}\right) \frac{1}{1-\beta \zeta}-u^{\prime}(\bar{c})\left(d_{0}^{i}-\bar{d}\right)
$$

Now imposing $V^{A R}\left(k, d^{1}, q^{* 1}\right)=V^{A R}\left(k, d^{2}, q^{* 2}\right)$, we get: 


$$
\begin{aligned}
& \sum_{t=0}^{\infty} \beta^{t} u(\bar{c})+u^{\prime}(\bar{c}) \bar{d}\left(q^{* 1}-\bar{q}\right) \frac{1}{1-\beta \zeta}-u^{\prime}(\bar{c})\left(d^{1}-\bar{d}\right) \\
= & \sum_{t=0}^{\infty} \beta^{t} u(\bar{c})+u^{\prime}(\bar{c}) \bar{d}\left(q^{* 2}-\bar{q}\right) \frac{1}{1-\beta \zeta}-u^{\prime}(\bar{c})\left(d^{2}-\bar{d}\right) \\
\Rightarrow & \left(d^{2}-\bar{d}\right)-\left(d^{1}-\bar{d}\right)=\frac{1}{1-\beta \zeta} \bar{d}\left(\left(q^{* 2}-\bar{q}\right)-\left(q^{* 1}-\bar{q}\right)\right) \\
\Rightarrow & d^{2}-d^{1}=\frac{1}{1-\beta \zeta} \bar{d}\left(q^{* 2}-q^{* 1}\right) \\
\Rightarrow & \frac{d^{2}-d^{1}}{\bar{d}}=\frac{q^{* 2}-q^{* 1}}{1-\beta \zeta}
\end{aligned}
$$

\section{A.8 Proposition 10}

Proof. Consider that productivity follows the $\xi$-process, so that $A_{0}=A^{\xi}$ and for $t>0$ :

- if $A_{t-1}=A^{\xi}, \operatorname{Pr}\left(A=A^{\xi}\right)=\xi$ and $\operatorname{Pr}(A=\bar{A})=1-\xi$;

- if $A_{t-1}=\bar{A}, A_{t}=\bar{A}$.

The value function at $(k, d)$ if $A_{t}=A^{\xi}$ is:

$$
V^{\xi}\left(k, d, A^{\xi}\right)=\max _{k^{\prime}, d^{\prime}, d^{\prime} \xi}\left\{u(c)+\beta\left[(1-\xi) V^{\operatorname{det}}\left(k^{\prime}, d^{\prime}\right)+\xi V^{\xi}\left(k^{\prime}, d^{\prime \xi}, A^{\xi}\right)\right]\right\}
$$

where $c=A^{\xi} f(k)+(1-\delta) k-k^{\prime}-d+q^{*}\left(d^{\prime}(1-\xi)+\xi d^{\prime \xi}\right)$ and $V^{\text {det }}$ is the value function in the model with no uncertainty.

A Taylor approximation of $V^{\xi}\left(\bar{k}, \bar{d}, A^{\xi}\right)$ around the deterministic steady state $\left(V^{\operatorname{det}}(\bar{k}, \bar{d})\right)$ yields:

$$
V_{\text {pay }}^{\xi}\left(\bar{k}, \bar{d}, A^{\xi}\right)=u(\bar{c})+u^{\prime}(\bar{c})\left(A^{\xi}-\bar{A}\right) f(k)+\beta(1-\xi) V^{\operatorname{det}}(\bar{k}, \bar{d})+\beta \xi V^{\xi}\left(\bar{k}, \bar{d}, A^{\xi}\right)
$$

where $\bar{c}=\bar{A} f(\bar{k})-\delta \bar{k}-\left(1-q^{*}\right) \bar{d}$.

So:

$$
V_{\text {pay }}^{\xi}\left(\bar{k}, \bar{d}, A^{\xi}\right)-V^{\operatorname{det}}(\bar{k}, \bar{d})=u^{\prime}(\bar{c})\left(A^{\xi}-\bar{A}\right) f(k)+\beta \xi\left[V_{\text {pay }}^{\xi}\left(\bar{k}, \bar{d}, A^{\xi}\right)-V^{\operatorname{det}}(\bar{k}, \bar{d})\right]
$$

which yields:

$$
V_{\text {pay }}^{\xi}\left(\bar{k}, \bar{d}, A^{\xi}\right)=V^{\operatorname{det}}(\bar{k}, \bar{d})+\frac{u^{\prime}(\bar{c})\left(A^{\xi}-\bar{A}\right) f(k)}{1-\beta \xi}
$$

If $d^{\xi}$ is close to $\bar{d}, V_{\text {pay }}^{\xi}\left(\bar{k}, d^{\xi}, A^{\xi}\right)$ can be written as:

$$
V_{\text {pay }}^{\xi}\left(\bar{k}, d^{\xi}, A^{\xi}\right)=V^{\operatorname{det}}(\bar{k}, \bar{d})+\frac{u^{\prime}(\bar{c})\left(A^{\xi}-\bar{A}\right) f(k)}{1-\beta \xi}-u^{\prime}(\bar{c})\left(d^{\xi}-\bar{d}\right)
$$


Out of the equilibrium path, the value function conditional on default is:

$$
V_{d e f}^{\xi}\left(k, \gamma, A^{\xi}\right)=\max _{k^{\prime}}\left\{u(c)+\beta\left[(1-\xi) V_{d e f}^{\operatorname{det}}\left(k^{\prime}, \gamma\right)+\xi V_{d e f}^{\xi}\left(k^{\prime}, \gamma, A^{\xi}\right)\right]\right\}
$$

where $c=(1-\gamma) A^{\xi} f(k)+(1-\delta) k-k^{\prime}$ and $V_{d e f}^{\text {det }}$ is the value function in the model with no uncertainty if the country decides to default.

A Taylor approximation of $V_{d e f}^{\xi}\left(\bar{k}, \gamma, A^{\xi}\right)$ around the deterministic steady state $\left(V_{\operatorname{def}}^{\operatorname{det}}(\bar{k}, \gamma)\right)$ yields:

$$
V_{d e f}^{\xi}\left(\bar{k}, \gamma, A^{\xi}\right)=u\left(\bar{c}_{d}\right)+u^{\prime}\left(\bar{c}_{d}\right)\left(A^{\xi}-\bar{A}\right)(1-\gamma) f(k)+\beta(1-\xi) V_{d e f}^{\operatorname{det}}(\bar{k}, \gamma)+\beta \xi V_{d e f}^{\xi}\left(\bar{k}, \gamma, A^{\xi}\right)
$$

where $\bar{c}_{d}=(1-\gamma) \bar{A} f(\bar{k})-\delta \bar{k}$, which yields:

$$
V_{d e f}^{\xi}\left(\bar{k}, \gamma, A^{\xi}\right)=V_{d e f}^{\operatorname{det}}(\bar{k}, \gamma)+\frac{u^{\prime}\left(\bar{c}_{d}\right)(1-\gamma)\left(A^{\xi}-\bar{A}\right) f(k)}{1-\beta \xi}
$$

Using an argument similar to Lemma 6 , if $\xi=1-2 \psi$ and fluctuations of technology are small, $V^{h}\left(k, d, A^{h}\right)=V^{\xi}\left(k, d, A^{h}\right)$ and an argument similar to Proposition ?? shows that if the country is constrained, $d^{\xi}$ and $\bar{d}$ are such that $V_{\text {pay }}^{\xi}\left(k^{\prime}, d^{\xi}\right)=V_{d e f}^{\xi}\left(k^{\prime}, \gamma\right)$ and $V_{\text {pay }}^{\operatorname{det}}\left(k^{\prime}, \bar{d}\right)=V_{\text {def }}^{\operatorname{det}}\left(k^{\prime}, \gamma\right)$. We want to know the values of $d^{\xi}$ and $\bar{d}$ that make such equalities hold when we are close to the deterministic steady state.

Using Equations 13 and 14, $V_{p a y}^{\operatorname{det}}(\bar{k}, \bar{d})=V_{\text {def }}^{\operatorname{det}}(\bar{k}, \gamma)$ imply:

$$
\begin{aligned}
V_{\text {pay }}^{\xi}\left(\bar{k}, d^{\xi}, A^{\xi}\right)= & V_{d e f}^{\xi}\left(\bar{k}, \gamma, A^{\xi}\right)-\frac{u^{\prime}\left(\bar{c}_{d}\right)(1-\gamma)\left(A^{\xi}-\bar{A}\right) f(k)}{1-\beta \xi} \\
& +\frac{u^{\prime}(\bar{c})\left(A^{\xi}-\bar{A}\right) f(k)}{1-\beta \xi}-u^{\prime}(\bar{c})\left(d^{\xi}-\bar{d}\right) \\
= & V_{d e f}^{\xi}\left(\bar{k}, \gamma, A^{\xi}\right)+\frac{\left[\gamma u^{\prime}(\bar{c})+u^{\prime}(\bar{c})-u^{\prime}\left(\bar{c}_{d}\right)\right]\left(A^{\xi}-\bar{A}\right) f(k)}{1-\beta \xi}-u^{\prime}(\bar{c})\left(d^{\xi}-\bar{d}\right)
\end{aligned}
$$

From Proposition 4:

$$
V_{\text {pay }}^{\operatorname{det}}(\bar{k}, \bar{d})=V_{d e f}^{\operatorname{det}}(\bar{k}, \gamma) \Rightarrow \bar{d}=\frac{\gamma A f(\bar{k})}{1-q^{*}}
$$

which implies $\bar{c}_{d}=\bar{c}$.

So $V_{\text {pay }}^{\xi}\left(\bar{k}, d^{\xi}, A^{\xi}\right)=V_{d e f}^{\xi}\left(\bar{k}, \gamma, A^{\xi}\right)$ if:

$$
\begin{aligned}
\frac{\left(1-q^{*}\right) \bar{d}}{\bar{A} f(\bar{k})} u^{\prime}(\bar{c}) \frac{\left(A^{\xi}-\bar{A}\right) f(k)}{1-\beta \xi} & =u^{\prime}(\bar{c})\left(d^{\xi}-\bar{d}\right) \Rightarrow \\
\frac{\left(1-q^{*}\right) \bar{d}}{1-\beta \xi} \frac{\left(A^{\xi}-\bar{A}\right)}{\bar{A}} & =d^{\xi}-\bar{d}
\end{aligned}
$$

Using $\xi=1-2 \psi$ and substituting $\left(A^{\xi}, d^{\xi}\right)$ for $\left(A^{h}, d^{h}\right)$ and $\left(A^{l}, d^{l}\right)$ we get 2 equations that relate debt and productivity at each of the two states. Combining both equations, we get Equation 10. 


\section{B Numerical examples}

\section{B.1 Deterministic model}

In the numerical examples of this paper, specific utility and production functional forms are assumed as follows:

$$
u(c)=\frac{c^{1-\sigma}}{1-\sigma} \quad, \quad f(k)=k^{\alpha}
$$

I calibrate the specific parameters as follows: one period corresponds to one year. $A=1, \alpha=0.36, \beta=1.02^{-1}, \sigma=3$ and $\delta=0.10$. The price of a riskless bond, $q^{*}$, equals $\beta$. The output loss in terms of default, $\gamma=0.01$.

The numerical solution is obtained through value function iteration. The state space is discretised using grids for debt and capital but the planner can choose any point in the grid. From Figure 2, the numbers obtained in this solution are very similar to those from the analytical formulae using the path of $y_{t}$ given by the numerical example.

Figure 2 also shows the behaviour of capital in this economy, $\gamma=0.01$, compared to the closed-economy case, $\gamma=0$, and the full-commitment open-economy case, $\gamma=1$. Without the possibility of default, the level of capital jumps to its steady state level and the marginal productivity of capital equals $r^{*}$ in one period. The possibility of default makes convergence slower. Due to the initial capital inflow, the level of capital is higher in this economy than in the closed economy case until they converge. However, the closed economy slowly catches up, as the open economy will be experiencing net capital outflows (trade balance surpluses) during the whole history, as shown at Figure 2. Debt stabilises at $51 \%$ of GDP but reaches $60 \%$ of GDP at earlier stages.

A usual intuition is that financially open economies should converge faster to their steady states (Barro, Mankiw and Sala-i-Martin, 1995). In contrast, the equilibrium from this model shows that an indebted open economy would take more time to converge than a closed economy with the same level of capital. After the initial capital inflow, the country experiences net outflows of resources i.e. a positive trade balance. In addition, a closed economy that opens to capital flows would not converge significantly faster but, on the way towards the steady state, would have higher output than if it remained closed. In order to experience faster convergence, emerging economies need trade deficits and, as Proposition 4 shows, that does not occur in equilibrium.

\section{B.2 Stochastic model}

In this section, the accuracy of the analytical approximations used in Section 4.2 is checked using numerical simulations. 

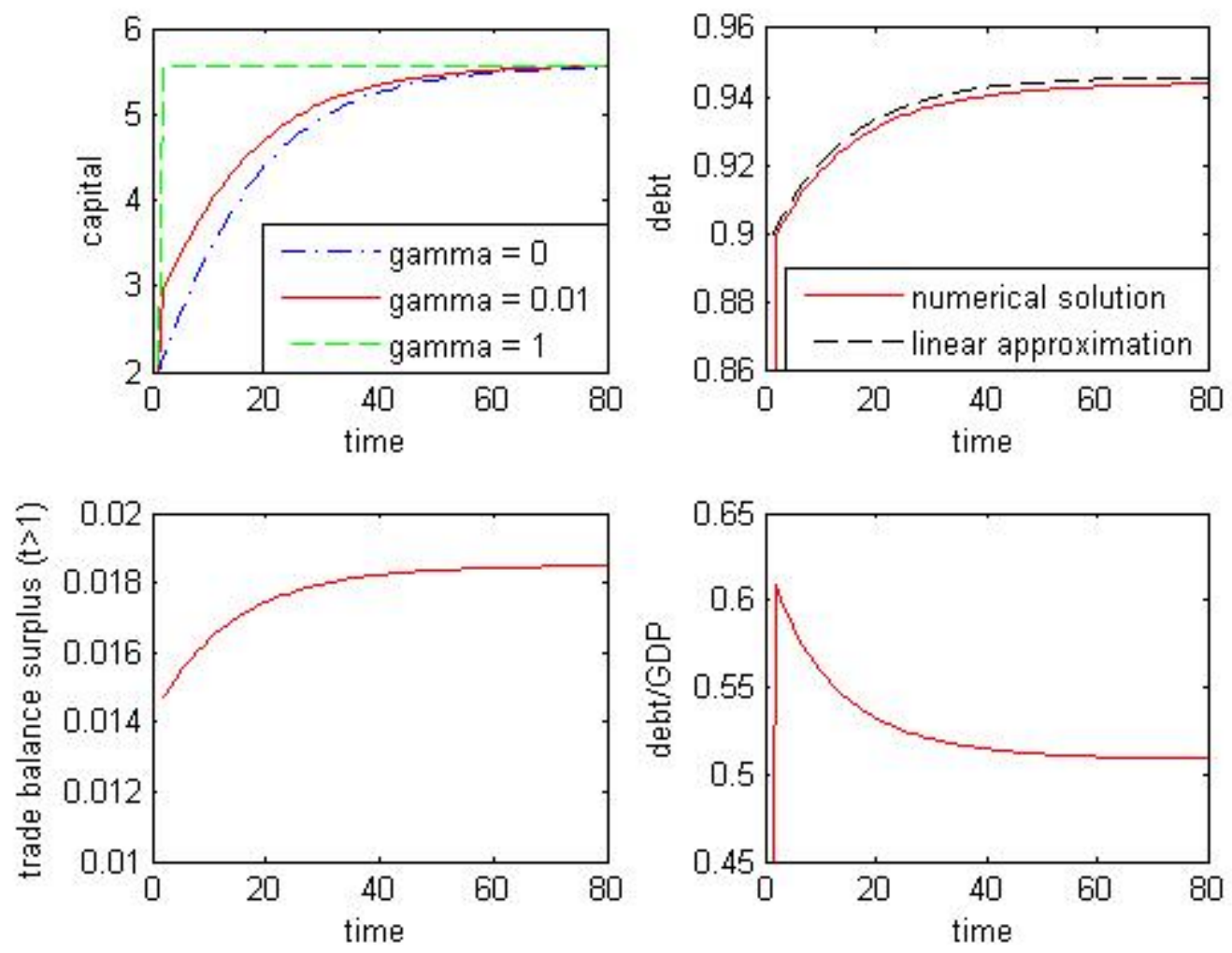

Figure 2: Deterministic model

I want to obtain the values of $\Delta d / d^{\prime}$ that make $V^{h}\left(k^{\prime}, d^{h}\right)=V^{l}\left(k^{\prime}, d^{l}\right)$ at every state $(k, d)$. The numerical solution is obtained through value function iteration. The state space is discretised using grids for debt and capital but the planner can choose any point in the grid. At the beginning of each iteration, $\Delta d$ is calculated to make $V^{h}\left(k^{\prime}, d^{h}\right)=$ $V^{l}\left(k^{\prime}, d^{l}\right)$.

I use the same stylisation of the 1970's and 1980's to calibrate the model: one period correspond to one year, $\alpha=0.36, \beta=1.02^{-1}, \gamma=0.01, \sigma=3$ and $\delta=0.10 . A=1$, and $q^{*}$ fluctuates around $\beta: q^{* l}=1.04^{-1}$ and $q^{* h}=1.00$. I constrain $k^{\prime}-k$ to lie in some interval - adjustment costs for capital are zero in that interval and infinity outside it. Figure 3 shows $\Delta d / d^{\prime}$ as a function of the marginal productivity of capital if the borrowing constraint is binding and the state is high in two situations: (a) $k^{\prime}-k \in(-0.10 k, 0.10 k)$ and (b) $k^{\prime}-k \in(-0.05 k, 0.10 k)$.

The main results are as follows:

- For $m p k>0.04=r^{* l}$, the linear approximation works well: $\Delta d / d^{\prime}$ is around 0.17 


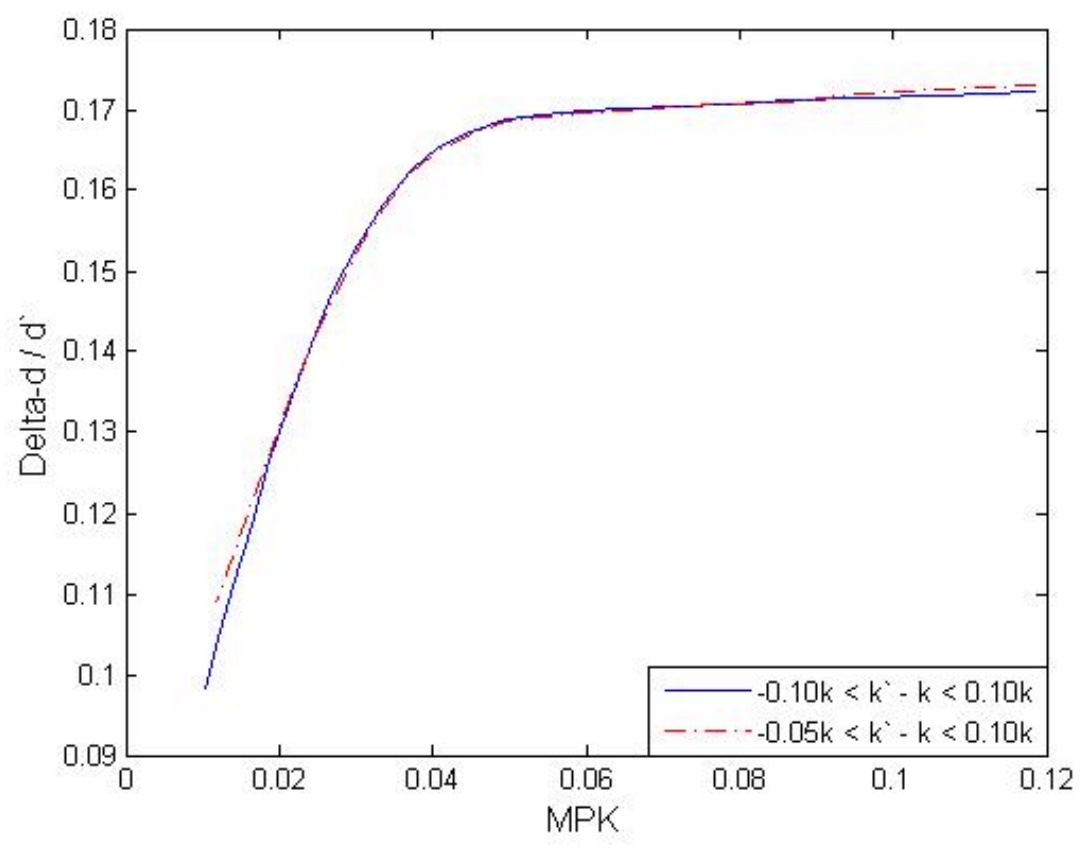

Figure 3: Debt relief

and gradually increasing in $m p k$. The possibility of borrowing an additional unit in the high state is worth slightly more to countries with high $m p k$.

- For $m p k$ below $r^{* l}=4 \%, \Delta d / d^{\prime}$ is considerably smaller. For lower values of $m p k$, when the state shifts to low, interest rates are higher than $m p k$, so the country sells capital and could even end up buying high-interest-rate foreign bonds. This might sound unrealistic because adjustment costs for capital would prevent such rapid capital movement. Indeed, the debt reduction $\Delta d / d^{\prime}$ for lower values of $m p k$ are sensitive to the assumptions on adjustment costs. Figure 3 shows that when $m p k$ is at its lowest value, $k^{\prime}=k$, then $\Delta d / d^{\prime}$ is around 0.10 with adjustment costs given by (a) and around 0.11 in case (b).

\section{References}

[1] Aguiar, Mark and Gopinath, Gita, 2006, "Defaultable debt, interest rates and the current account", Journal of International Economics 69, 64-83.

[2] Alfaro, Laura and Kanczuk, Fabio, 2005, "Sovereign debt as a contingent claim: a quantitative approach", Journal of International Economics 65, 297-314. 
[3] Alvares, Fernando and Jermann, Urban, 2000, "Efficiency, equilibrium, and asset pricing with risk of default", Econometrica 68, 775-797.

[4] Atkeson, Andrew, 1991, "International lending with moral hazard and risk of repudiation", Econometrica 59, 1069-1089.

[5] Arellano, Cristina, 2008, "Default risk and income fluctuations in emerging economies", American Economic Review 98, 690-712.

[6] Barro, Robert; Mankiw, N. Gregory and Sala-i-Martin, Xavier, 1995, "Capital mobility in neoclassical models of growth", American Economic Review 85, 103-115.

[7] Bolton, Patrick and Jeanne, Olivier, 2007, "Structuring and restructuring sovereign debt: the role of a bankruptcy regime", Journal of Political Economy 115, 901-924.

[8] Borensztein, Eduardo and Mauro, Paulo, 2004, "The case for GDP-indexed bonds", Economic Policy 2004, 165-216.

[9] Bulow; Jeremy and Rogoff, Kenneth, 1989, "A constant recontracting model of sovereign debt", Journal of Political Economy 97, 155-178.

[10] Calvo, Guillermo and Kaminsky, Graciela, 1991, "Debt relief and debt rescheduling", Journal of Development Economics 36, 5-36.

[11] Calvo, Guillermo; Leiderman, Leonardo and Reinhart, Carmen, 1996, "Inflows of Capital to Developing Countries in the 1990s", Journal of Economic Perspectives 10, n.2, 123-139.

[12] Caselli, Francesco and Feyrer, James, 2007, "The marginal product of capital", Quarterly Journal of Economics 122, 535-568.

[13] Cline, William, 1995, "International debt reexamined", Institute for International Economics.

[14] Cohen, Daniel and Sachs, Jeffrey, 1986, "Growth and external debt under risk of debt repudiation", European Economic Review 1986, 529-560.

[15] Diaz-Alejandro, Carlos, 1984, "Latin American debt: I don't think we are in Kansas anymore", Brookings Papers on Economic Activity 2:1984, 335-389.

[16] Dotsey, Michael; Lantz, Carl and Scholl, Brian, 2003, "The behavior of the real rate of interest", Journal of Money, Credit and Banking 35, 91-110. 
[17] Eaton, Jonathan and Gersovitz, Mark, 1981, "Debt with potential repudiation: theoretical and empirical analysis", Review of Economic Studies 48, 289-309.

[18] English, William, 1996, "Understanding the costs of sovereign default: American state debts in the 1840's", American Economic Review 86, 259-275.

[19] Fernandez, Raquel and Rosenthal, Robert, 1990, "Strategic models of sovereign debt renegotiations", Review of Economic Studies 57, 331-349.

[20] Fischer, S., 1999, "On the need for an international lender of last resort", Journal of Economic Perspectives 13:4, 85-104.

[21] Foley-Fisher, Nathan, 2008, "Optimal debt and default in an economy with a natural resource endowment", mimeo.

[22] Foley-Fisher, Nathan and Guimaraes, Bernardo, 2009, "US real interest rates and default risk in emerging economies", mimeo.

[23] Grossman, Herschel and Van Huyck, John, 1988, "Sovereign debt as a contingent claim: excusable default, repudiation, and reputation", American Economic Review 78, 1088-1097.

[24] Jeske, Karsten, 2006, "Private international debt with risk of repudiation", Journal of Political Economy 114, 576-593.

[25] Kehoe, Patrick and Perri, Fabrizio, 2004, "Competitive equilibria with limited enforcement", Journal of Economic Theory 119, 184-206.

[26] Kletzer, Kenneth; Newbery, David and Wright, Brian, 1992, "Smoothing primary exporters' price risk: bonds, futures, options and insurance", Oxford Economic Papers 44, 641-671.

[27] Kocherlakota, Narayana, 1996, "Implications of efficient risk sharing without commitment", Review of Economic Studies 63, 595-609.

[28] Kovrijnykh, Natalia and Szentes, Balazs, 2007, "Equilibrium default cycles", Journal of Political Economy 115, 403-446.

[29] Krueger, Anne, 2002, "A New Approach to Sovereign Debt Restructuring", IMF.

[30] Lucas, Robert, 1990, "Why doesn't capital flow flow rich to poor countries", American Economic Review 80, 92-96. 
[31] Marcet, Albert and Marimon, Ramon, 1992, "Communication, commitment and growth", Journal of Economic Theory 58, 219-249.

[32] Neumeyer, Pablo Andres and Perri, Fabrizio, 2005, "Business cycles in emerging economies: the role of interest rates", Journal of Monetary Economics 52, 345-380.

[33] Reinhart, Carmen and Rogoff, Kenneth, 2004, "Serial Default And The 'Paradox' Of Rich To Poor Capital Flows", American Economic Review 94, 52-58.

[34] Reinhart, Carmen; Rogoff, Kenneth and Savastano, Miguel, 2003, "Debt Intolerance", Brookings Papers on Economic Activity 1:2003, 1-74.

[35] Sturzenegger, Federico and Zettelmeyer, Jeromin, 2006, "Debt defaults and lessons from a decade of crises", MIT Press.

[36] Tomz, Michael, 2007, "Reputation and international cooperation", Princeton University Press.

[37] Tomz, Michael and Wright, Mark, 2007, "Do countries default in 'bad times'?", Journal of the European Economic Association 5, 352-60.

[38] Uribe, Martin and Yue, Vivian, 2006, "Country spreads and emerging countries: who drives whom?", Journal of International Economics 69, 6-36.

[39] Yue, Vivian, 2010, "Sovereign default and debt renegotiation", Journal of International Economics 80, 176-187. 